\title{
Viable Materials with a Giant Magnetocaloric Effect
}

\author{
Nikolai A. Zarkevich ${ }^{1, *(\mathbb{D}}$ and Vladimir I. Zverev ${ }^{2} \mathbb{D}$ \\ 1 Ames Laboratory, U.S. Department of Energy, Ames, IA 50011, USA \\ 2 Physics Department, M. V. Lomonosov Moscow State University, 119991 Moscow, Russia; \\ vi.zverev@physics.msu.ru \\ * Correspondence: zarkev@ameslab.gov or zarkev@gmail.com
}

Received: 3 September 2020; Accepted: 12 September 2020; Published: 15 September 2020

\begin{abstract}
This review of the current state of magnetocalorics is focused on materials exhibiting a giant magnetocaloric response near room temperature. To be economically viable for industrial applications and mass production, materials should have desired useful properties at a reasonable cost and should be safe for humans and the environment during manufacturing, handling, operational use, and after disposal. The discovery of novel materials is followed by a gradual improvement of properties by compositional adjustment and thermal or mechanical treatment. Consequently, with time, good materials become inferior to the best. There are several known classes of inexpensive materials with a giant magnetocaloric effect, and the search continues.
\end{abstract}

Keywords: magnetocaloric; economically viable; solid; materials for energy conversion

\section{Introduction}

A change of temperature $T$ can be converted to electricity [1]. A significant fraction of consumed electricity is used for heat pumping, which results in a targeted cooling or heating [2]. Magnetocaloric materials have a growing role in facilitating these energy transformations [3-5].

Under adiabatic condition, when there is no heat exchange between a material and the environment, a change of internal entropy $\Delta S$ of a material by an external stimulus is compensated by a change in its temperature $\Delta T$. This phenomenon is called the caloric effect, which is typically the largest at a phase transition. Examples of phase transitions include liquid-gas (evaporation), solid-liquid (melting), and solid-solid transformations - the last ones include structural, magnetic, and magnetostructural transitions in solids. The magnetocaloric effect (MCE) consists in a reversible change of temperature of a magnetic solid upon exposure to a varying external magnetic field [5-12].

Liquid-gas phase transitions are used in vapor-compression refrigeration [13]. A solid-liquid phase transition in isentropically compressed Helium-3 is used for Pomeranchuk cooling to sub-Kelvin temperatures [14,15]. Solid-solid phase transitions in magnetocaloric materials can be used for energy transformations: for cooling and heat pumping $[10,16,17]$ at various $T$, including cryogenic and room temperature (RT), as well as for generating electricity from a changing temperature [1,18]. There is a hope that use of caloric materials will lead to a more cost-effective, energy-efficient, and environmentally friendly alternative to the traditional vapor-compression refrigeration [3].

A magnitude of the magnetocaloric effect (in terms of an isentropic temperature change $\Delta T_{S}$ or an isothermal entropy change $\Delta S_{T}$ ) depends on a material and an applied magnetic field $H$. Typically, magnetocaloric effect is maximal at the phase transition between two states with different net magnetization and different total entropy, which combines electronic (including magnetic) and lattice (phonon) contributions [19]. There is no strict definition of a giant magnetocaloric effect, which is giant relative to that in known materials. The number of known materials (composed from a finite set of chemical elements, see Figure 1) and the largest known MCE increase with time, see Figure 2. 


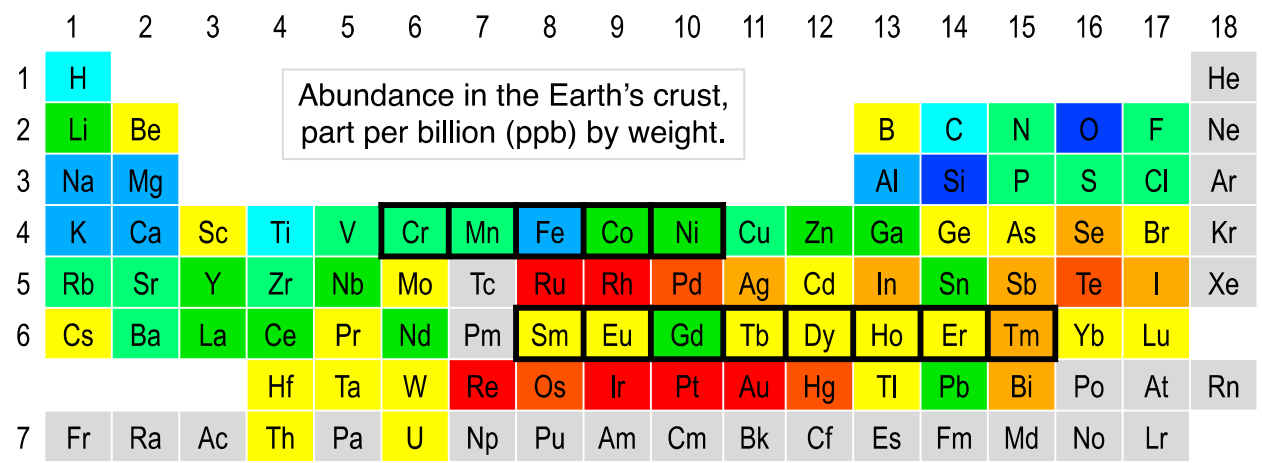

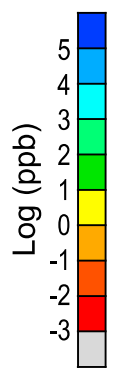

Figure 1. Periodic Table with abundances of chemical elements in solids of the Earth's upper crust. Marked are the most magnetic elements (atoms or ions in neutral or partially oxidized states).
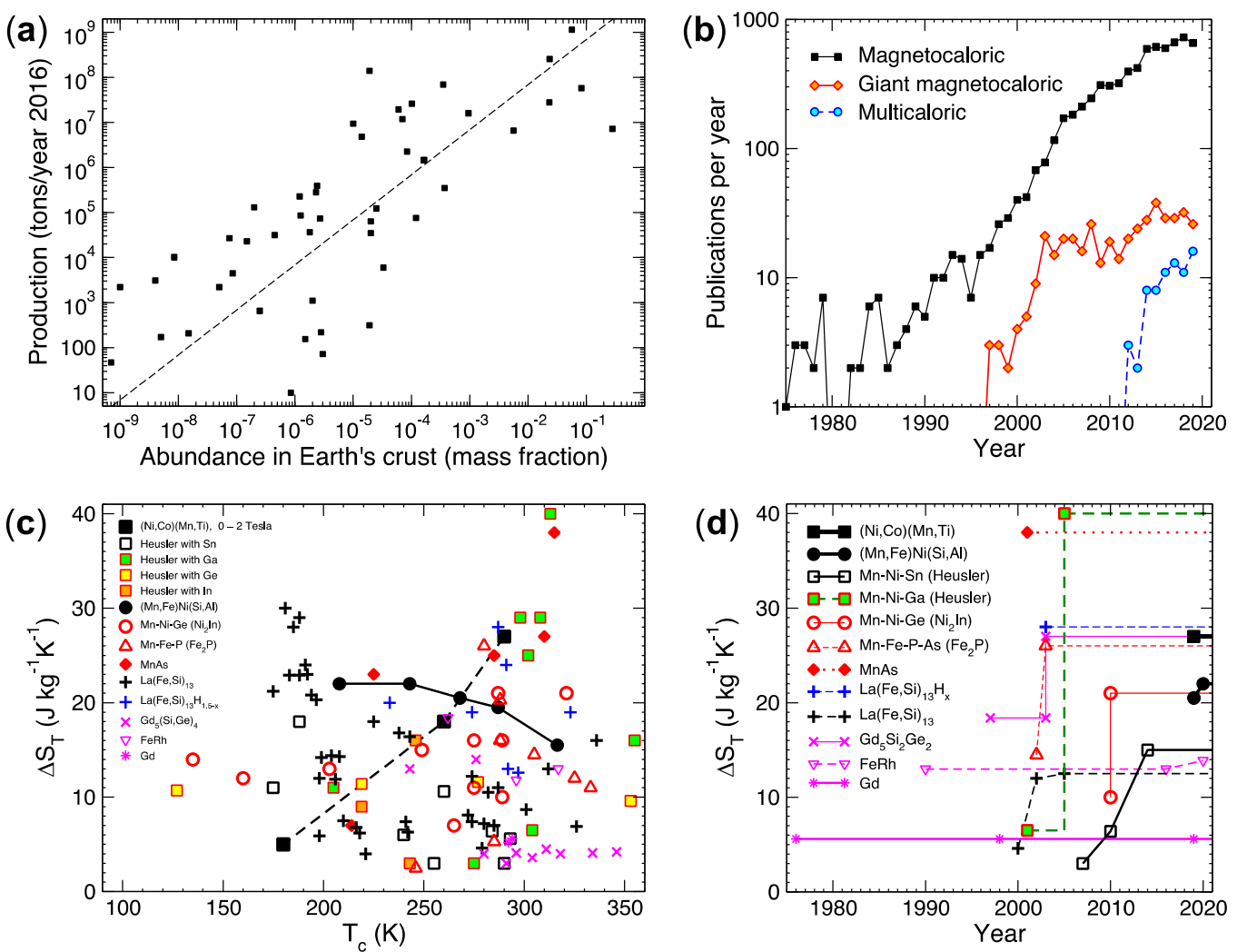

Figure 2. (a) Correlation between global annual production and abundance of chemical elements in the upper crust of the Earth. (b) The number of publications per year on magnetocalorics, a giant magnetocaloric effect and a multicaloric effect in the subject (title, abstract, and keywords) in the Web of Science core collection. (c) The isothermal entropy change $\Delta S_{T}\left(\mathrm{~J} \mathrm{~kg}^{-1} \mathrm{~K}^{-1}\right)$ at 2 Tesla (20 kOe) magnetic field change versus phase transition temperature $T_{\mathcal{c}}(\mathrm{K})$. (d) Timeline for the selected classes of magnetocaloric materials: $\Delta S_{T}$ at 2 Tesla near room $T$ versus time. Viable materials made from abundant non-toxic elements are represented by black symbols. Colored are critical or toxic materials; hydrides (blue) emit $\mathrm{H}_{2}$ gas.

Magnetocaloric materials are magnetic: they have constituting atoms with non-zero atomic magnetic moments $M_{a}$. In a nonmagnetic (NM) state, atomic magnetic moments are zero and there is no net magnetization. A ferromagnetic (FM) state is characterized by a magnetic long-range order (LRO) of the parallelly aligned atomic magnetic moments $M_{a}$ and a net magnetization $M \neq 0$. In a ferrimagnetic (FiM) state with LRO, antiparallel alignment of atomic magnetic moments with different amplitudes also results in a nonzero net magnetization. Zero net magnetization is obtained from an 
antiparallel alignment of nonzero atomic magnetic moments with the same amplitudes (but opposite directions) in an antiferromagnetic (AFM) state with LRO. A paramagnetic (PM) state has a zero net magnetization due to orientationally disordered directions of nonzero atomic magnetic moments, which may have short range order (SRO), but no LRO. Sometimes, a PM state is approximated by a homogeneously random uncorrelated distribution of disordered local moments (DLM) without SRO and without LRO. Orientations of atomic moments dynamically change with time in a PM state, which differs from a spin glass with a static magnetic structure.

Dynamic orientational disorder of nonzero atomic magnetic moments results in a nonzero magnetic entropy, which is large in a PM state. In contrast, magnetic entropy is negligible in the LRO states with ordered magnetic alignment (FM, FiM, AFM, and NM).

The MCE is characterized by the isentropic temperature change $\Delta T_{S}$, which increases with the isothermal change of the total entropy $\Delta S_{T}$. A large MCE is typically observed in magnetic or magnetostructural phase transitions between a highly magnetic (FM or FiM) and a weakly magnetic (PM or AFM) states. The change of magnetic entropy is large in a transition between the PM state and any state with magnetic LRO (FM, FiM, or AFM). However, magnetic contribution to the total entropy competes with electronic and lattice contributions. In theory, the total entropy change $\Delta S_{T}$ is expected to be maximal in a magnetostructural phase transition between FM and PM states in a material with large atomic magnetic moments, if magnetic, electronic, and lattice entropy changes sum in $\Delta S_{T}$ with the same signs and sufficient amplitudes. In practice, if any particular contribution to $\Delta S_{T}$ is large, then the MCE can be large even if the other contributions are small. For example, in spite of a negligible difference in magnetic entropy between the FM and AFM states (both have LRO and a small magnetic entropy), the difference in the total entropy can be large due to a dominant contribution of electronic entropy [20], which is proportional to the total electronic density of states (DOS) at the Fermi energy $E_{F}[19]$.

History of a giant magnetocaloric effect near room temperature probably starts from the theoretical prediction [20] of a giant change of electronic entropy in the isostructural metamagnetic phase transition between the FM and AFM states in FeRh, followed by direct experimental observation [21] of a drop in temperature in a quenched near-stoichiometric $\mathrm{Fe}_{49} \mathrm{Rh}_{51}$ sample, later confirmed by other measurements [22-24]. The prediction [20] was based on the earlier measurements $[25,26]$ of magnetic properties and unpaired spin densities in the Fe-Rh alloys.

In spite of an implementation of the caloric cooling using the second-order phase transition in metallic gadolinium [27], followed by the observation of a large MCE in expensive FeRh alloy containing precious rhodium, a broad interest remained dormant until the discovery of a giant MCE in $\mathrm{Gd}_{5} \mathrm{Si}_{2} \mathrm{Ge}_{2}$ [28], see Figure 2b,d. After an extensive search [29], other materials with a giant MCE were found. Most of them contained critical, rare, or toxic elements, see Figure 2c. However, to be viable for industry, magnetocaloric materials should be made from inexpensive, abundant, and safe elements [30,31].

The cost of a material combines prices of its constituents, manufacturing, shipping, and handling, and can be further increased by taxation and human greed. With caution, estimated prices of chemical elements can be used to evaluate the lower bound on the cost of a materials. The market price is expected to form as a balance between supply and demand. Chemical composition is not the only factor determining the price. For example, cheap coal and expensive diamonds are composed predominantly by carbon, a chemical element which is quite common, see Figure 1.

Cheap and abundant materials are typically made from abundant elements. In general, more abundant elements are mined in larger quantities. Global production of chemical elements correlates with their abundance in the upper crust, see Figure 2a. For the profitable production of a material, its market price should be higher than the sum of the prices of constituents, cost of manufacturing, processing, shipping and handling, and added expenses due to a monopoly in mining or distribution, as well as political risks (the last are significant for the rare earth). Poisonous or toxic materials are more expensive to handle during the whole life cycle of materials and products. 
Magnetic materials contain atoms or ions with nonzero atomic magnetic moments $M_{a}$. Magnetocaloric materials with a large MCE typically contain a large atomic fraction of magnetic ele-ments, such as $f$-metals (Gd, Tb, Dy, Ho, Er, Tm, Eu, Sm) or $d$-metals ( $\mathrm{Mn}, \mathrm{Fe}, \mathrm{Co}, \mathrm{Ni}, \mathrm{Cr}$ ) with a partially filled $f$ or $d$ band, see Figure 1. Magnetization in the FM state and magnetic entropy in the PM state correlate with the amplitudes of atomic moments $M_{a}$, which are large near half-filling of $f$ or $d$ band (e.g., in Gd or Mn in a neutral state). Electronic entropy correlates with electronic DOS at $E_{F}$, which is large near $\frac{1}{4}$ or $\frac{3}{4}$ filling of $f$ or $d$ band.

Thus, elemental abundance, toxicity, safety, electronic structure, and magnetism impose constraints on composition of magnetocaloric materials, viable for industry. For example, most of the $f$-metals (except for the relatively cheap La and Ce) are rare critical materials, and their use in mass production is undesired. Due to toxicity, undesired are As and $\mathrm{Sb}$.

A material is economically viable if it is available (people can make it), affordable (can be obtained for a reasonable price), machinable (can be processed using existing equipment), non-toxic, ecological, and (most importantly) useful. Historically, the first discovered materials with a large MCE contained expensive or rare elements. Although scientifically interesting [32,33], they were not economically viable. It was a challenge to discover magnetocaloric materials made of abundant and non-toxic elements [30,31]. For example, in the CaloriCool approach [3,29] over $10^{4}$ (ten thousand) magnetic phase transformations were rapidly screened and less than $10^{2}$ (hundred) systems were pre-selected, out of which $<10$ were labeled as the most promising, but only two materials were patented [34,35]. The preferable choice of compositions was based on elemental abundance, shown in Figure 1. Disregarded were compositions containing critical or toxic chemical elements, as well as gas-emitting hydrides. Recent discoveries [30,31] of a giant MCE in materials without critical or toxic elements enable production and use of such materials in large quantities.

\section{Materials with a Giant MCE}

How large should be a "giant" MCE? One can claim a giant effect if it competes with or exceeds that in known materials. In 1997, the MCE in $\mathrm{Gd}_{5} \mathrm{Si}_{2} \mathrm{Ge}_{2}$ [28] was giant, because it exceeded MCE in the known at that time [36] rare metallic Gd [27,37] and precious FeRh [21], see Figure 2d.

There are thousands of magnetocaloric publications, including hundreds of those mentioning a giant caloric effect, see Figure $2 \mathrm{~b}$. However, most considered materials are not economically viable, because they contain precious metals (Rh, Pd) [21,22,24], rare earth [12,38-41], expensive germanium [42,43] or gallium [28,44], toxic elements [45-51], or hydrogen [52-55], which is released in a gas phase, see Figure 2c. Before 2005, a large MCE (exceeding that in metallic Gd) was claimed in precious FeRh [21,22], expensive $\mathrm{Gd}_{5} \mathrm{Si}_{2} \mathrm{Ge}_{2}$ [28,56-68] and related materials ( $\mathrm{GdGe}_{4}[69,70], \mathrm{GdSn}_{4}$ [71,72], $\mathrm{Tb}_{5} \mathrm{Si}_{2} \mathrm{Ge}_{2}$ [73]), Heusler alloys [74] containing $\mathrm{Ga}$, partially hydrated $\mathrm{La}(\mathrm{Fe}, \mathrm{Si})_{13} \mathrm{H}_{1.5-\mathrm{x}}$ [52,53], toxic $\mathrm{MnAs}_{1-\mathrm{x}} \mathrm{Sb}_{\mathrm{x}}[45-47,75]$, $\mathrm{MnFeP}_{0.45} \mathrm{As}_{0.55}[48,49], \mathrm{Mn}_{1.82} \mathrm{~V}_{0.18} \mathrm{Sb}$ [50], and other materials [76-79].

Table 1. Composition (with critical or undesired elements, if any), caloric response $\Delta S_{T}\left(\mathrm{~J} \mathrm{~kg}^{-1} \mathrm{~K}^{-1}\right.$ ) and $\Delta T_{S}(\mathrm{~K})$ at 2 Tesla magnetic field change, phase transition $T_{c}(\mathrm{~K})$, and hysteresis width $\Delta T_{h}(\mathrm{~K})$.

\begin{tabular}{cccccccc}
\hline Composition & $\boldsymbol{\Delta} \boldsymbol{S}_{\boldsymbol{T}}$ & $\boldsymbol{T}_{\boldsymbol{c}}(\mathbf{K})$ & $\boldsymbol{\Delta} \boldsymbol{T}_{\boldsymbol{S}}(\mathbf{K})$ & $\boldsymbol{\Delta} \boldsymbol{T}_{\boldsymbol{h}}(\mathbf{K})$ & Critical & Ref. & Year \\
\hline $\mathrm{Ni}_{37.5} \mathrm{Co}_{12.5} \mathrm{Mn}_{35} \mathrm{Ti}_{15}$ & 27 & 290 & & & - & {$[30]$} & 2019 \\
$\mathrm{Ni}_{36.3} \mathrm{Co}_{13.7} \mathrm{Mn}_{35} \mathrm{Ti}_{15}$ & 18 & 260 & & - & {$[30]$} & 2019 \\
$\mathrm{Ni}_{35} \mathrm{Co}_{15} \mathrm{Mn}_{35} \mathrm{Ti}_{15}$ & 5 & 180 & & - & {$[30]$} & 2019 \\
$\mathrm{Mn}_{0.5} \mathrm{Fe}_{0.5} \mathrm{NiSi}_{0.95} \mathrm{Al}_{0.05}$ & 15.5 & 316.5 & & - & {$[31]$} & 2019 \\
$\mathrm{Mn}_{0.5} \mathrm{Fe}_{0.5} \mathrm{NiSi}_{0.945} \mathrm{Al}_{0.055}$ & 19.5 & 287 & & - & {$[31]$} & 2019 \\
$\mathrm{Mn}_{0.5} \mathrm{Fe}_{0.5} \mathrm{NiSi}_{0.94} \mathrm{Al}_{0.06}$ & 20.5 & 268 & & - & {$[31]$} & 2019 \\
$\mathrm{Mn}_{0.5} \mathrm{Fe}_{0.5} \mathrm{NiSi}_{0.935} \mathrm{Al}_{0.065}$ & 22 & 243 & & - & {$[31]$} & 2019 \\
$\mathrm{Mn}_{0.5} \mathrm{Fe}_{0.5} \mathrm{NiSi}_{0.93} \mathrm{Al}_{0.07}$ & 22 & 208 & & - & {$[31]$} & 2019 \\
$\mathrm{Mn}_{0.5} \mathrm{Fe}_{0.5} \mathrm{NiSi}_{0.94} \mathrm{Al}_{0.06} \mathrm{~B}_{0.05}$ & 22 & 283 & & & - & {$[31]$} & 2020 \\
$\mathrm{Ni}_{44.5} \mathrm{Mn}_{37} \mathrm{Fe}_{6.7} \mathrm{Sn}_{11.8}$ & 5.6 & 293 & & & - & {$[80]$} & 2010 \\
$\mathrm{Ni}_{44.2} \mathrm{Mn}_{39.3} \mathrm{Fe}_{4.9} \mathrm{Sn}_{11.6}$ & 6.4 & 284 & & & - & {$[80]$} & 2010 \\
\hline
\end{tabular}


Table 1. Cont.

\begin{tabular}{|c|c|c|c|c|c|c|c|}
\hline Composition & $\Delta S_{T}$ & $T_{c}(\mathrm{~K})$ & $\Delta T_{S}(\mathrm{~K})$ & $\Delta T_{h}(\mathrm{~K})$ & Critical & Ref. & Year \\
\hline $\mathrm{Ni}_{44.4} \mathrm{Mn}_{44.1} \mathrm{Sn}_{11.5}$ & 10.6 & 260 & & & - & [80] & 2010 \\
\hline $\mathrm{Ni}_{50.2} \mathrm{Mn}_{35.0} \operatorname{In}_{14.8}$ & 18 & 301 & 1.2 & 3.6 & In & [81] & 2016 \\
\hline $\mathrm{Ni}_{49.6} \mathrm{Mn}_{35.6} \operatorname{In}_{14.8}$ & 7.5 & 268 & 1.6 & 7.9 & In & [81] & 2016 \\
\hline $\mathrm{Ni}_{45.7} \mathrm{Mn}_{36.6} \mathrm{Co}_{4.2} \operatorname{In}_{13.5}$ & 10.5 & 289 & 3.0 & 10 & In & [82] & 2015 \\
\hline $\mathrm{Ni}_{55.4} \mathrm{Mn}_{20} \mathrm{Ga}_{24.6}$ & 40 & 313 & 1.5 & 8 & $\mathrm{Ga}$ & [74] & 2005 \\
\hline $\mathrm{MnFeP}_{0.45} \mathrm{As}_{0.55}$ & 14.5 & 300 & & $1^{1}$ & As 4 & [50] & 2002 \\
\hline MnAs & 38 & 315 & & & $\mathrm{As}^{4}$ & [45] & 2001 \\
\hline $\mathrm{La}_{0.7} \mathrm{Ca}_{0.3} \mathrm{MnO}_{3}$ & 5.7 & 260 & 2.3 & -0 & - & [83] & 2019 \\
\hline $\mathrm{La}(\mathrm{Fe}, \mathrm{Co}, \mathrm{Al})_{13}$ & - & $0-400$ & - & - & - & [84] & 1992 \\
\hline $\mathrm{LaFe}_{11.4} \mathrm{Si}_{1.6}$ & $14^{1}$ & 209 & & & - & [85] & 2000 \\
\hline $\mathrm{LaFe}_{11.4} \mathrm{Si}_{1.6}$ & 14.3 & 208 & & & - & [86] & 2001 \\
\hline $\mathrm{LaFe}_{11.4} \mathrm{Si}_{1.6}$ & 14.2 & 199 & & & - & [87] & 2009 \\
\hline $\mathrm{LaFe}_{11.7} \mathrm{Si}_{1.3}$ & 25 & 188 & 4 & 2 & - & [88] & 2005 \\
\hline $\mathrm{LaFe}_{11.2} \mathrm{Co}_{0.7} \mathrm{Si}_{1.1}$ & 12.5 & 274 & 2.4 & 2 & - & [88] & 2005 \\
\hline $\mathrm{LaFe}_{11.12} \mathrm{Co}_{0.711} \mathrm{Al}_{1.17}$ & 4.6 & 279 & & & - & [85] & 2000 \\
\hline $\mathrm{La}\left(\mathrm{Fe}_{0.96} \mathrm{Co}_{0.04}\right)_{11.9} \mathrm{Si}_{1.1}$ & 16.4 & 243 & & & - & [89] & 2005 \\
\hline $\mathrm{La}\left(\mathrm{Fe}_{0.88} \mathrm{Co}_{0.12}\right)_{13} \mathrm{H}_{1.5}$ & 19 & 323 & 6.8 & $1^{1}$ & $\mathrm{H}^{5}$ & [52] & 2003 \\
\hline $\mathrm{La}\left(\mathrm{Fe}_{0.89} \mathrm{Co}_{0.11}\right)_{13} \mathrm{H}_{1.3}$ & 24 & 291 & 6.9 & $1^{1}$ & $\mathrm{H}^{5}$ & [52] & 2003 \\
\hline $\mathrm{La}\left(\mathrm{Fe}_{0.9} \mathrm{Co}_{0.1}\right)_{13} \mathrm{H}_{1.1}$ & 28 & 287 & 7.1 & $1^{1}$ & $\mathrm{H}^{5}$ & [52] & 2003 \\
\hline $\mathrm{Fe}_{49} \mathrm{Rh}_{51}{ }^{3}$ & & 313 & -12.9 & 8.5 & $\mathrm{Rh}^{6}$ & [21] & 1990 \\
\hline $\mathrm{Fe}_{49} \mathrm{Rh}_{51}$ & $13^{1}$ & 317 & $-9.2^{2}$ & $10^{1}$ & $\mathrm{Rh}^{6}$ & [24] & 2016 \\
\hline $\mathrm{Fe}_{49} R h_{51}$ & 13.9 & & & & $\mathrm{Rh}^{6}$ & [23] & 2020 \\
\hline $\mathrm{Gd}_{5} \mathrm{Si}_{2} \mathrm{Ge}_{2}$ & 18.4 & 262 & 4.9 & 5 & $\mathrm{Gd}, \mathrm{Ge}$ & [28] & 1997 \\
\hline $\mathrm{Gd}_{5} \mathrm{Si}_{2} \mathrm{Ge}_{2}$ & 15 & 277 & $5^{1}$ & & $\mathrm{Gd}, \mathrm{Ge}$ & [63] & 2003 \\
\hline $\mathrm{Gd}_{5} \mathrm{Si}_{2} \mathrm{Ge}_{2}{ }^{3}$ & 27 & 270 & 7 & & $\mathrm{Gd}, \mathrm{Ge}$ & [63] & 2003 \\
\hline $\mathrm{Gd}_{5} \mathrm{Si}_{4}$ & 4.2 & 346 & & & $\mathrm{Gd}$ & [90] & 2001 \\
\hline $\mathrm{Gd}$ & $6^{1}$ & 293 & $4^{1}$ & -0 & $\mathrm{Gd}$ & [27] & 1976 \\
\hline $\mathrm{Gd}$ & 5.6 & 294 & $5^{1}$ & -0 & $\mathrm{Gd}$ & [38] & 1998 \\
\hline $\mathrm{Gd}$ & 5.2 & 292 & 4.7 & -0 & $\mathrm{Gd}$ & [91] & 2019 \\
\hline
\end{tabular}

${ }^{1}$ Approximate value. ${ }^{2} \Delta T_{S}$ reduces from $9.2 \mathrm{~K}$ to $6.2 \mathrm{~K}$ during cycling in field of 1.9 Tesla. ${ }^{3}$ Heat treated. ${ }^{4}$ Arsenic is toxic. ${ }^{5}$ Hydrides emit $\mathrm{H}_{2}$ gas. ${ }^{6}$ Rhodium is precious.

Known materials made of abundant and non-toxic elements include those with body-centered cubic (bcc) A2, B2 [30], or Heusler structures [80,92-103] (with or without a possible tetragonal distortion), $\mathrm{Mn}_{0.5} \mathrm{Fe}_{0.5} \mathrm{NiSi}_{1-\mathrm{x}} \mathrm{Al}_{\mathrm{x}}$ [31] with TiNiSi-type orthorhombic to $\mathrm{Ni}_{2}$ In-type hexagonal phase transition, $\mathrm{LaFe}_{13-x} \mathrm{Si}_{x}[87,104,105]$ with the $\mathrm{NaZn}_{13}$-type 1:13 phase (Figure 3), a subset of magnetic shape memory alloys (SMA) containing $\mathrm{Ni}$ and $\mathrm{Mn}$, manganites based on $\mathrm{La}_{0.7} \mathrm{Ca}_{0.3} \mathrm{MnO}_{3}$, etc.

The MCE depends on crystal structure. A subset of crystal structures of giant magnetocaloric materials is shown in Figure 3. Importantly, materials with a close-packed structure, such as the face centered cubic (fcc) or hexagonal close-packed (hcp), are less likely to show a giant MCE, because atomic magnetic moments $M_{a}$ become smaller at a smaller volume per atom. A suppression of MCE by anisotropy was reported for metallic Gd [106]. In general, materials with larger $M_{a}$ are more responsive to a changing external magnetic field. Continued increase of diversity of considered structures is an important task of materials discovery. 


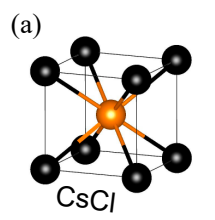

(d)

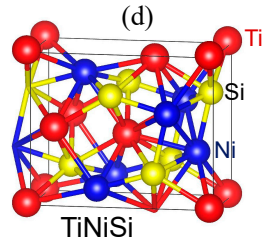

(b)
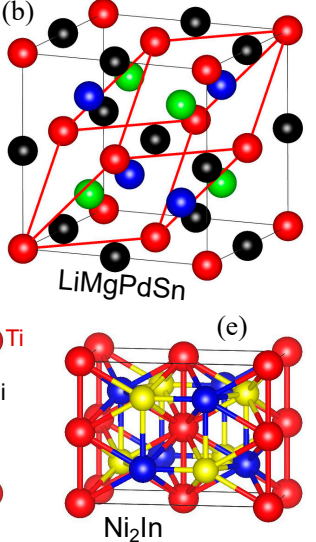

(c)

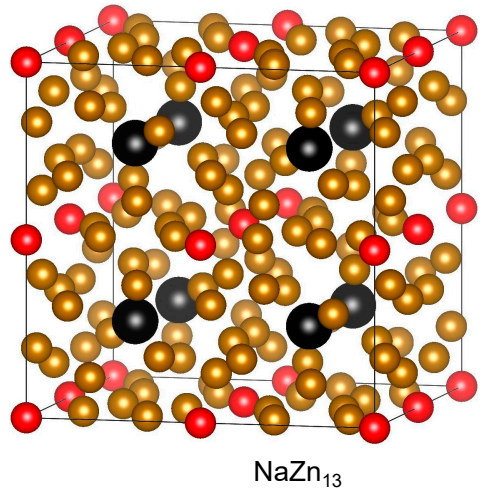

Figure 3. Crystal structures: (a) cubic CsCl-type binary B2 (with nearest-neighbor bonds); (b) LiMgPdSn-type quaternary Heusler (red lines show 4-atom primitive unit cell); (c) cubic $\mathrm{NaZn}_{13}$-type $\mathrm{La}(\mathrm{Fe}, \mathrm{Si})_{13}$ (La is black, $\mathrm{Fe}_{1}$ is red, $\mathrm{Fe}_{2}$ sites occupied by $\mathrm{Fe}+\mathrm{Si}$ are orange); (d) TiNiSi-type orthorhombic ternary structure; and (e) $\mathrm{Ni}_{2}$ In-type hexagonal structure in orthorhombic supercell $\left(\mathrm{Ni}_{1}\right.$ is red, $\mathrm{Ni}_{2}$ is blue, In is yellow). Images are prepared using VESTA software (https://jp-minerals.org/vesta).

The MCE depends not only on composition and structure, but also on atomic ordering, which is controlled by thermal history of a sample. For example, a quenched FeRh sample showed a larger MCE than an annealed one [21]. A dependence of MCE on atomic LRO was observed in B2 Ni-Co-Mn-Ti alloys [30] and other materials [107]. Figure 3a,b shows binary B2 and quaternary Heusler structures decorating the same bcc lattice; these structures differ by atomic ordering. Typically, experimental samples with the Heusler structure are not fully ordered. Figure $3 \mathrm{~d}$,e shows the low- $T$ orthorhombic and the high- $T$ hexagonal structures of $\mathrm{Mn}_{0.5} \mathrm{Fe}_{0.5} \mathrm{NiSi}_{1-\mathrm{x}} \mathrm{Al}_{\mathrm{x}}$ [31], which has atomic disorder on $(\mathrm{Mn}, \mathrm{Fe})$ and $(\mathrm{Si}, \mathrm{Al})$ sublattices. The MCE is a function of many parameters, which include composition, structure, atomic ordering, temperature, and applied external fields. Due to the multi-dimensional parametric space, direct comparison of MCE in different materials can be tricky [108].

There is a significant progress in discovery and understanding of materials with a giant magnetocaloric effect $[19,24,30,31,39,43,75,79,81,82,85,92-100,107,109-294]$, see Figure 2. Many among the considered materials are scientifically interesting [295], but not economically viable. A few contain precious $\mathrm{Rh}$ (e.g., FeRh $[24,222,278,279]$ and $\mathrm{Tb}_{3} \mathrm{Rh}$ [270]). Many contain critical rare earth, such as $\mathrm{Eu}$ in $\mathrm{Eu}_{2} \mathrm{In}$ [140], $\mathrm{EuTiO}_{3}$ [114,135,156,195] doped with Al [113], Cr [196], Mn [134], Co [151], Ni [119], Ba [157,206], Nb [110,170,195] and $\mathrm{Eu}$ in other compounds [133, 232,240,251]; $\mathrm{Gd}$ in $\mathrm{GdAlO}_{3}$ [158], $\mathrm{GdFeO}_{3}$ [138,162], $\mathrm{GdCrO}_{3}$ [183], $\mathrm{GdCrO}_{4}-\mathrm{ErCrO}_{4}$ [202], $\mathrm{GdScO}_{3}$ [117,124], $\mathrm{Gd}_{2} \mathrm{CoMnO}_{6}$ [155], $\mathrm{Gd}_{2} \mathrm{BaNiO}_{5}$ [152], $\mathrm{GdCrTiO}_{5}$ [143], $\mathrm{GdCo}_{2} \mathrm{~B}_{2}$ [271], $\mathrm{GdCoC}_{2}$ [171], $\mathrm{RuSr}_{2} \mathrm{GdCu}_{2} \mathrm{O}_{8}$ [208], etc.; $\mathrm{Tb}$ in $\mathrm{TbFeO}_{3}$ [176], $\mathrm{TbMn}_{2} \mathrm{O}_{5}$ [179], $\mathrm{Tb}_{2} \mathrm{CoMnO}_{6}$ [132], $\mathrm{Tb}_{5} \mathrm{Ge}_{2-x} \mathrm{Si}_{2-\mathrm{x}} \mathrm{Mn}_{2 \mathrm{x}}$ [255], $\mathrm{Tb}_{4} \mathrm{Gd}_{1} \mathrm{Si}_{2.035} \mathrm{Ge}_{1.935} \mathrm{Mn}_{0.03}$ [197], etc.; Dy in $\mathrm{DyAl}_{2}$ [275], DySb [263], $\mathrm{DyNi}_{2} \mathrm{~B}_{2} \mathrm{C}$ [250], Dy $0.9 \mathrm{Tm}_{0.1} \mathrm{Ni}_{2} \mathrm{~B}_{2} \mathrm{C}$ superconductor [272], DyNiSi [181], DyCuSi [266], $\mathrm{DyFeO}_{3}$ [199], $\mathrm{DyCrO}_{4}$ [230], $\mathrm{DyVO}_{4}$ [209], etc.; Ho in thin Ho films [248], $\mathrm{HoMn}_{2} \mathrm{O}_{5}$ [127,221], $\mathrm{Ho}_{3} \mathrm{Al}_{2}$ [237], $\mathrm{HoCuAl}$ [224], $\mathrm{Ho}_{12} \mathrm{Co}_{7}$ [223], HoCoGe [166], HoCoSi [235], HoCuSi [268], HoGa [267], $\mathrm{Ho}_{2} \mathrm{PdSi}_{3}$ [194], $\mathrm{Ho}_{5} \mathrm{Pd}_{2}$ [187], amorphous HoErGdCuNi [112], etc.; $\mathrm{Er}$ in ErNiBC [243], $\mathrm{ErCr}_{2} \mathrm{Si}_{2}$ [244], $\mathrm{ErMn}_{2} \mathrm{Si}_{2}$ [242], $\mathrm{ErRu}_{2} \mathrm{Si}_{2}$ [286], ErRuSi [234], $\mathrm{Er}_{2} \mathrm{Mn}_{2} \mathrm{O}_{7}$ [164], $\mathrm{ErK}\left(\mathrm{MoO}_{4}\right)_{2}$ [188], amorphous $\mathrm{Er}_{x} \mathrm{Co}_{1-x}$ [220], etc.; $\mathrm{Tm}$ in TmZn [198] and metallic glasses [233]; rare earth in clathrates [277,296], etc. Manganites [258] include $\mathrm{La}_{0.7} \mathrm{Ca}_{0.3} \mathrm{MnO}_{3}[227,262,264,285], \mathrm{La}_{0.48} \mathrm{Ca}_{0.52} \mathrm{MnO}_{3}$ [174], Na-deficient $\mathrm{La}_{0.8} \mathrm{Na}_{0.2-x} \mathrm{MnO}_{3}$ [185], $\mathrm{La}_{0.67} \mathrm{Sr}_{0.16} \mathrm{Ca}_{0.17} \mathrm{MnO}_{3}$ [207], $\mathrm{La}_{0.8-\mathrm{x}} \mathrm{K}_{\mathrm{x}} \mathrm{Ba}_{0.05} \mathrm{Sr}_{0.15} \mathrm{MnO}_{3}$ [297], as well as containing critical rare earth $\mathrm{La}_{0.7-x} \mathrm{Pr}_{\mathrm{x}} \mathrm{Ca}_{0.3} \mathrm{MnO}_{3}$ [160], $\mathrm{GdMnO}_{3}$ [186], $\mathrm{Gd}_{2} \mathrm{NiMnO}_{6}$ and $\mathrm{Gd}_{2} \mathrm{CoMnO}_{6}$ [193], $\mathrm{TbMnO}_{3}$ [165,252], $\mathrm{DyMnO}_{3}$ [247], PrPb manganites [294], etc. Materials containing highly toxic arsenic include MnAs [123,131,210,238,245,246,256,265,273,276,282,289] and MnFe(P,As) [48,49,239,298]. However, interest is shifting towards less toxic materials without $\mathrm{As}$, such as $(\mathrm{Mn}, \mathrm{Fe})_{2}(\mathrm{P}, \mathrm{Si})[125,126,150]$ doped 
with Ge [109,205] or B [184,201,215]. Examples with toxic antimony include $\mathrm{Mn}_{1.9} \mathrm{Co}_{0.1} \mathrm{Sb}$ [211], $\mathrm{Mn}_{2-\mathrm{x}} \mathrm{Cr}_{\mathrm{x}} \mathrm{Sb}$ [236], $\mathrm{NiMn}_{0.9} \mathrm{Sb}_{0.1}$ [254], $\mathrm{Ni}_{0.5-\mathrm{x}} \mathrm{Co}_{\mathrm{x}} \mathrm{Mn}_{0.38} \mathrm{Sb}_{0.12}$ [92], etc. Hydrides emit $\mathrm{H}_{2}$ gas [52-55]. A giant MCE was found in cobalt hydroxides $\mathrm{Co}(\mathrm{OH})_{2}[212,259,280]$. Ni-Mn-Ga alloys [169,213,253] contain expensive Ga. Mn-Fe-Ge [287], Mn-Ni-Ge [121] and Mn-Co-Ge [116,129,168,173,178,182] contain critical Ge [231]; these alloys can be doped with In [141], Si [159] and Fe [111,120,142]; Ge was successfully substituted by (Si,Al) [31]. Magnetic shape memory alloys [148,204] include Ni-Mn-In [167, 175,192,261,283] doped with Co [136,172,241] and Si [122]; Ni-Mn-Sn [115,226]; NiMn-based B2 (Ni-Co)(Mn-Ti) [30], Ni-Co-Mn-Al films [189,190] and Heusler $\mathrm{Ni}_{40} \mathrm{Co}_{10} \mathrm{Mn}_{36} \mathrm{Al}_{14}$ [100]; Ni-Co-Mn-Sn alloys, such as $\mathrm{Ni}_{40} \mathrm{Co}_{10} \mathrm{Mn}_{41} \mathrm{Sn}_{9}$ [146], $\mathrm{Ni}_{40} \mathrm{Co}_{10} \mathrm{Mn}_{40} \mathrm{Sn}_{10}$ [214], $\mathrm{Ni}_{42.8} \mathrm{Mn}_{40.3} \mathrm{Co}_{5.7} \mathrm{Sn}_{11.2}$ [219], $\mathrm{Ni}_{40} \mathrm{Co}_{10} \mathrm{Mn}_{40} \mathrm{Sn}_{9} \mathrm{Al}_{1}$ [144], and $\mathrm{Ni}_{42-x} \mathrm{Ti}_{\mathrm{x}} \mathrm{Co}_{9} \mathrm{Mn}_{39} \mathrm{Sn}_{10}$ [153]. A large MCE was found in amorphous $\mathrm{Fe}_{78-x} \mathrm{Cr}_{x} \mathrm{Si}_{4} \mathrm{Nb}_{5} \mathrm{~B}_{12} \mathrm{Cu}_{1}$ [281], $\mathrm{Fe}_{73.5-\mathrm{x}} \mathrm{Cr}_{\mathrm{x}} \mathrm{Si}_{13.5} \mathrm{~B}_{9} \mathrm{Nb}_{3} \mathrm{Cu}_{1}$ [293], and metallic glasses [274]. Significant interest was devoted to the potentially viable $\mathrm{LaFe}_{13-x} \mathrm{Si}_{x}[137,200,284,288,290,292]$, doped with Co [249] and other additives [35], or partially hydrated [52-55]. For completeness, we mention $\mathrm{Mn}_{3} \mathrm{CuN}_{1-\mathrm{x}} \mathrm{C}_{\mathrm{x}}$ [147] and molecular magnets [128].

One can see trends towards increasing MCE, replacing toxic elements, and eliminating expensive and critical elements, leading to a cost reduction of the best-in-class materials $[30,31,296]$. Discussed applications of magnetocaloric materials include cooling and heat pumping [2-8,299-301], as well as energy generation [1]. MCE can be used for the thermo-magneto-electric energy transformations, such as conversion of energy into a temperature change [3-6], or conversion of a changing temperature [1] into a changing magnetic field, which generates voltage in a coil [18].

One can use thermodynamic estimators [19] for systematic screening of caloric materials [29]. It is convenient to store properties in a database [302]. Properties of the best-in-class materials are compared in Figure 2c. An historic timeline is presented in Figure 2d. Table 1 augments data from the reviews $[83,303]$. Next, we proceed to consideration of the properties and relations among them.

\section{Properties}

\subsection{Thermodynamic Relations}

The caloric effect results in heat generation or absorption, when an external field is applied, and the subsystem changes its entropy. In the adiabatic process, which happens without transfer of heat or mass between a thermodynamic system and its surrounding, this leads to an isentropic change in temperature by $\Delta T_{S}$. At adiabatic switching-off of a magnetic field there is a demagnetization of a ferromagnetic material, i.e., destruction of a magnetic order that leads to increase of magnetic entropy. This, in turn, leads to an adjustment in the lattice temperature by $\Delta T_{S}$, because the process of magnetic order destruction (demagnetization) in the subsystem of magnetic moments requires energy, which is supplied by a crystal lattice. Thus, during adiabatic magnetization and demagnetization of the substance, there is a reversible process of heat transfer from the magnetic subsystem to the lattice and vice versa. Thus, MCE is the result of an entropy change in magnetic subsystem under the influence of an applied external magnetic field. The total entropy $S$ of a magnetic material, in which magnetization is formed due to localized magnetic moments, can be represented as the sum of the lattice $S_{L}$ and electronic (including magnetic) parts $S_{e}=S_{e l}+S_{M}$-the last includes magnetic contribution $S_{M}$. At constant pressure $P$, all three components are functions of temperature $T$ [5],

$$
S(T, H)_{P}=\left[S_{L}(T, H)+S_{e l}(T, H)+S_{M}(T, H)\right]_{P} .
$$

Among them, magnetic entropy is highly dependent on the magnetic field $H$, while "pure" electronic $S_{e l}$ and lattice $S_{L}$ contributions are usually almost independent on the field $H$ near room $T$.

Under adiabatic conditions (in an isentropic process) the total entropy is not changed, therefore

$$
\Delta S_{M}(T, H)_{P}=-\left[\Delta S_{e l}(T, H)+\Delta S_{L}(T, H)\right]_{P} .
$$


The separation of the lattice vibrational (phonon) entropy $S_{L}$ is possible if one neglects the electron-phonon interactions, which have a noticeable effect on the spectrum of electronic excitations. Using the Debye temperature $\theta_{D}$, the lattice entropy can be calculated from Debye's interpolation:

$$
S_{L}=-3 R\left[\ln \left(1-e^{-\theta_{D} / T}\right)+12\left(\frac{T}{\theta_{D}}\right)^{3} \int_{0}^{\theta_{D} / T} \frac{x^{3} d x}{e^{x}-1}\right] .
$$

If the change of the electronic contribution $S_{e l}$ in the magnetic field $H$ is insignificant, then $\Delta S_{M}$ is linked mainly to the change of the lattice entropy $\Delta S_{L}$. However, in itinerant magnets containing $3 d$ metals a separation of the electronic and magnetic entropy into purely magnetic and electronic parts is difficult, because $d$-electrons forming local magnetic moments contribute to conductivity, and their contribution to the electronic density of states $n\left(E_{F}\right)$ at the Fermi energy $E_{F}$ is comparable with those from $p$ and s-electrons. The electronic (including magnetic) entropy can be estimated by the Sommerfeld's expansion:

$$
S_{e} \approx\left(\frac{\pi}{3}\right) k_{B}^{2} \operatorname{Tn}\left(E_{F}\right)
$$

The value of the electronic contribution to entropy can be calculated from experimental values of electronic heat capacity:

$$
S_{e l}=\gamma T,
$$

where $\gamma$ is the electronic heat capacity factor.

Let's consider the total entropy $S$ of a magnetic material at constant pressure $P$ as a function of temperature $T$ and magnetic field $H$. The exact differential of the total entropy is

$$
d S(T, H)_{P}=\left(\frac{\partial S}{\partial T}\right)_{H, P} d T+\left(\frac{\partial S}{\partial H}\right)_{T, P} d H
$$

The Maxwell relation [304]

$$
-\frac{\partial^{2} F}{\partial H \partial T}=\left(\frac{\partial S}{\partial H}\right)_{T, P}=\left(\frac{\partial M}{\partial T}\right)_{H, P}^{\prime}
$$

where $M$ is the magnetization of the system and $F$ is the free energy, allows to estimate the entropy change $\Delta S_{T}$ at constant $T$ by the thermal integration:

$$
\Delta S_{T}=\int_{H_{1}}^{H_{2}}\left(\frac{\partial M(T, H)}{\partial T}\right)_{H, P} d H
$$

The partial derivatives $\frac{\partial M}{\partial T}$ can be extracted from the processed experimental $M(H, T)$ data.

Let us consider various contributions to MCE. In the case of a ferromagnetic materials with two sublattices (e.g., $\mathrm{Tb}_{\mathrm{x}} \mathrm{Gd}_{1-\mathrm{x}}$ alloys at $x<0.8$ ), $\mathrm{MCE}$ includes contributions due to true magnetization (paraprocess), changes in the magnetic anisotropy energy, changes in the interlattice interaction between $\mathrm{Tb}$ and $\mathrm{Gd}$ sublattices, magnetostrictive deformations, domain boundary displacements, and irreversible processes. Each contribution depends on temperature, value and direction of the external field. However, it is possible to neglect several contributions, if they are small. The ones due to displacement and other irreversible processes are not experimentally observed. Estimates show that the contribution of magnetostrictive deformations is small (especially near the Curie temperature). Contributions due to paraprocess, anisotropy, and sublattice interaction play a significant role in $\mathrm{Tb}_{\mathrm{x}} \mathrm{Gd}_{1-\mathrm{x}}$ alloys. In the case of a ferromagnetic material, the work done to increase the magnetization of the domain $M_{D}=M_{S}+M_{I}$ (where $M_{I}$ is the change of the domain magnetization due to the paraprocess, $M_{S}$ is spontaneous magnetization), equals to $d W_{S}=-H d M_{D}$. 
From the second law of the thermodynamics, $d Q=T d S$, and from definition of the heat capacity $C=\left(\frac{d Q}{d T}\right)$ at constant external field, $C_{H}=\left(\frac{d Q}{d T}\right)_{H}=T\left(\frac{d S}{d T}\right)_{H^{\prime}}$ using Equations (6) and (7), one can find:

$$
T d S=C_{H} d T+T\left(\frac{\partial M}{\partial T}\right)_{H} d H
$$

In the adiabatic process $d S=0$, hence the isentropic temperature change [305] due to the magnetocaloric effect caused by a change of external magnetic field is

$$
\Delta T_{S}=T_{2}-T_{1}=-\int_{H_{1}}^{H_{2}} \frac{T}{C_{H}(T, H)} \times\left(\frac{\partial M(T, H)}{\partial T}\right)_{H} d H .
$$

Here, the integration is from $H_{1}$ to $H_{2} ; H_{1}$ is the initial field at which the initial sample's temperature is $T_{1}, H_{2}$ is the final field at which the final sample's temperature is $T_{2}$, and $C_{H}$ is the heat capacity at constant external fields. In general, the MCE due to the paraprocess in fields lower than those of technical saturation is extremely small. As a rule, a significant MCE is observed in magnetocaloric materials at field values that exceed the technical saturation field for a given material, and therefore in most practical cases the contribution due to the paraprocess is crucial. The absolute value of the magnetization derivative has an extremum at the phase transition temperature. Thus, the maximal MCE is observed near the phase transition temperature. This fact is associated with the correlations among the magnetothermal and other properties of magnetocaloric materials.

\subsection{Correlated Physical Properties}

Magnetothermal phenomena include the MCE, magnetic contributions to the heat capacity and entropy, as well as special parameters introduced to characterize magnetic nanoparticles in the method of magneto-liquid hyperthermia, such as specific absorption rate (SAR) and intrinsic loss parameter (ILP) [306,307]. These thermodynamic parameters quantify the key properties of a magnetic material: magnetization, heat capacity, magnetic susceptibility, etc. Knowledge of these dependencies allows to characterize a material and consider its practical applications.

From Equation (10), a field change $\Delta H=H_{2}-H_{1}$ causes an isentropic temperature change $\Delta T_{S}$ that depends on both $\frac{T}{C(T, H)_{P, H}}$ and $\left(\frac{\partial M(T, H)}{\partial T}\right)_{H}$. The MCE is large when $\left(\frac{\partial M(T, H)}{\partial T}\right)_{H}$ is large and $C(T, H)$ is small at the same $T$. The extremums of both $\left(\frac{\partial M(T, H)}{\partial T}\right)_{H}$ and $C(T, H)$ do not coincide in a general case. At an ideal first-order phase transition the derivative $\left(\frac{\partial M}{\partial T}\right)_{H}$ doesn't exist, and the listed equations are not fulfilled as they are derived from Landau theory [308] for the second-order phase transition. The mutual influence of these properties was considered in [309], with a theoretical estimate of the maximal possible magnetocaloric effect for bulk ferromagnetic materials with a second-order phase transition near the room temperature. It was demonstrated that the maximum MCE cannot exceed $18 \mathrm{~K} / \mathrm{T}$ in the ideal case, which is not achievable in practice. The estimates for realistic materials provide the maximum values from 8 to $10 \mathrm{~K} / \mathrm{T}$.

From the equation for heat capacity at constant pressure $C_{p}(T, H)=T\left(\frac{\partial S(T, H)}{\partial T}\right)_{H, P}$ and Equation (1),

$$
d S(T, H)_{P}=\frac{C_{L}(T)_{P}}{T} d T+\frac{C_{e l}(T)_{P}}{T} d T+\frac{C_{M}(T)_{P}}{T} d T+\left(\frac{\partial S_{M}(T, H)}{\partial H}\right)_{T, P} d H,
$$

where $C_{L}(T)$ is the lattice contribution to the heat capacity, $C_{e l}(T)$ is the electronic (without magnetic) contribution, $C_{M}(T, H)$ is the heat capacity of the magnetic subsystem. Thus, one can say that the heat capacity of a magnetic material is the sum of electronic, lattice, and magnetic heat capacities. The electronic and lattice heat capacity in most materials have a negligibly weak dependence on 
external magnetic field, while the magnetic contribution strongly depends on the applied magnetic field and therefore determines the MCE value.

As shown in $[11,310]$, the exact temperature at which MCE reaches its maximum in simple ferromagnetic materials should be above the temperature of the heat capacity maximum at zero magnetic field, due to the following equation:

$$
\Delta T_{S}(T, H)_{\max }=-T_{1} \Delta C(T, H)
$$

where

$$
\Delta C(T, H)=\frac{C\left(T_{1}, H\right)-C\left(T_{2}, H\right)}{C\left(T_{1}, H\right)} .
$$

Here, $T_{1}$ and $T_{2}$ are the initial and the final temperature of the sample, respectively.

In the case of low magnetic fields and relatively high temperatures (e.g., near room temperature), $\frac{\Delta T_{S}\left(T_{1}, H\right)_{\max }}{T_{1}}$ can be neglected. Thus, Equation (13) at $T_{\max }(H)$, where MCE reaches its extremum value, can be approximated:

$$
C\left(T_{\max }, H\right) \cong C\left(T_{2}, H\right)
$$

Magnetic materials can have several characteristic temperatures associated with magnetic transformations [11,310]. Nevertheless, the MCE sign is directly related to the sign of $d H_{c r} / d T$ derivative, where $H_{c r}$ is the critical field. For example, in Dy with a negative MCE in low fields the phase boundary shifts towards lower temperatures, see Figure 2 in [311].

Thus, a change in the sample temperature due to MCE cannot bring the sample to a new phase. In particular, Gd does not undergo the FM-PM transition when heated only due to the magnetocaloric effect; pure field transition in Gd is not observed experimentally, see Figure 1 in [311]. Accordingly, it can be assumed that the phase transformation shifts away from the transition temperature in zero field faster than MCE increases when the magnetic field is applied, that is, MCE cannot exceed the value of $d T_{d} d d H$, where $T_{\mathcal{c}}$ is the transition temperature.

For many magnetocaloric materials, the influence of the magnetic field on the MCE maximum value in high fields is known from literature. However, the behavior of anomalies of the magnetocaloric effect, magnetization, magnetic entropy change and heat capacity (in particular, their relative locations and field shifts relative to each other) in low fields still needs further investigated. For example, the heat capacity maximum typically shifts towards higher temperatures in strong magnetic fields [38]. At the same time, it is unclear why the temperature at which the heat capacity reaches its maximum in $2 \mathrm{~T}$ (Figure 7 of [38]) is obviously lower than the corresponding temperature for the zero-field dependence (see Figure 4).

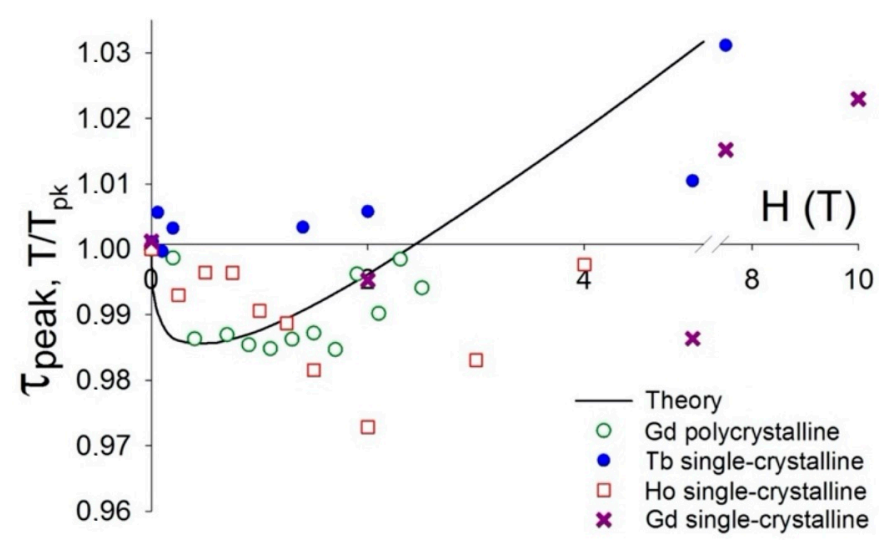

Figure 4. Position of the maximum in the magnetic heat capacity of gadolinium, terbium and holmium versus the applied magnetic field (Tesla). Theory [312] is compared to experimental data for Gd [38], $\mathrm{Tb}$ [313], and Ho [314]. 
In [312], the shift of the heat capacity maximum is investigated by means of Landau theory, and it is shown that in the weak fields below 2.4 Tesla the maximum shifts towards lower temperatures, while in stronger magnetic fields above $2.4 \mathrm{~T}$ it shifts in the opposite direction.

For simple ferromagnetic materials and for the known magnetic field change it is possible to determine a specific temperature $\Theta(H)$, in the vicinity of which the MCE maximum should be observed [310]. This temperature is higher than the temperature at which the heat capacity maximum is reached in zero magnetic field. If the magnetic field decreases in the adiabatic process, the MCE maximum is close to the characteristic temperature $\Theta(H)$, at which the magnetic field has no effect on heat capacity. In general, when magnetic order differs from the LRO (FM or AFM) state, or when more than one magnetic phase transition is observed, the MCE dependence on temperature becomes more complex (additional maxima and minima appear); its functional form depends on how many new extrema have appeared and where the characteristic temperatures $\Theta(H)$ are now located.

Figure 4 summarizes the displacements of the maximum in the magnetic heat capacity of gadolinium, terbium and holmium $[313,314]$, where $\mathrm{T} / \mathrm{T}_{\mathrm{pk}}$ is the ratio of the measured temperature to the temperature at which the maximum of the magnetic heat capacity in a given magnetic field is observed. The experimental data is compared with the theoretical line, taken from Figure 9 in [312]. There is a critical field value, at which the maximum begins to shift towards higher temperatures. Thus, the field-induced non-monotonic behavior of the maximum in the magnetic heat capacity is commonly expected for the rare earth metals, although there are exceptions (e.g., $\mathrm{Tb}$ ).

Physical properties are correlated, and there is a frequent combination of outstanding magnetothermal properties, such as the caloric effect and a property of another origin. Materials like NiTi show both shape memory and caloric effect at the phase transition $[315,316]$. This provides an inspiration to search for a giant MCE in magnetic shape memory alloys. FeRh alloys reveal a large MCE, a significant spontaneous volume magnetostriction [317] and magnetoresistance [318], and a remarkable decrease in electrical resistivity [319] in the vicinity of the AFM-FM transition. Similar correlations are observed in $\mathrm{Gd}_{5}\left(\mathrm{Si}_{x} \mathrm{Ge}_{1-\mathrm{x}}\right)_{4}$ alloys [320]. In addition, magnetic transformations are often accompanied by an abnormal thermal expansion [139,321,322]. The caloric effect also scales with the total entropy change. Many catalysts [323] have a large electronic density of states at the Fermi energy, and thus a large electronic entropy. Electronic entropy increases with electronic DOS at $E_{F}$ (see Equation (4)), affecting the caloric response.

\subsubsection{Multicaloric Effect}

A striking example of correlated physical properties in one material is the multicaloric effect. Caloric materials have a wide range of properties, among which there are the caloric effects associated with a reversible change of entropy (under isothermal conditions) or temperature (under adiabatic conditions) due to a variation of external fields (magnetic $H$, electric $E$, mechanical stress $\sigma$, or hydrostatic pressure $P$ ). The corresponding individual caloric effects caused by a variation of a single physical field are called magneto-, electro-, elasto-, and baro-caloric [324-326], respectively.

A phase transition can be driven by more than one external stimulus. If more than one physical field is capable to produce a caloric response, then such effect is called multicaloric [327]. The corresponding entropy change due to a simultaneous or sequential application of several fields is

$$
d S=\left(\frac{\partial S}{\partial H}\right)_{T, P, E} d H+\left(\frac{\partial S}{\partial E}\right)_{T, P, H} d E+\left(\frac{\partial S}{\partial P}\right)_{T, E, H} d P+\left(\frac{\partial S}{\partial T}\right)_{P, E, H} d T
$$

and consequently

$$
d S=-\frac{T}{C_{P, E, H}}\left[\left(\frac{\partial M}{\partial T}\right)_{P, E, H} d H+\left(\frac{\partial p}{\partial T}\right)_{P, E, H} d E-\left(\frac{\partial V}{\partial T}\right)_{P, E, H} d P\right] .
$$


Here, $M$ is magnetization, $p$ is polarization, $V$ is volume, $H$ is magnetic field, $E$ is electric field, $P$ is pressure, and $T$ is temperature.

In particular, magnetic transitions can be governed by a changing external magnetic field, while a transition between two phases with different densities (and different volume per formula unit) is affected by pressure. Also, a variable magnetic field can not only cause MCE, but also induce an electrical field, which in turn will change the polarization $p$ and generate an electro-caloric effect. At constant entropy $S$, the equation for this combined effect in a variable magnetic field is [327]

$$
d T_{S}=-\frac{T}{C(T, H)_{P, E, H}}\left[\frac{\alpha_{m}}{\varepsilon_{0} \chi^{e}}\left(\frac{\partial p}{\partial T}\right)_{P, E, H}+\left(\frac{\partial M}{\partial T}\right)_{P, E, H}\right] d H .
$$

Here, $\alpha_{\mathrm{m}}$ is the direct magnetoelectric interaction ratio in $d E=\alpha_{m}\left(\varepsilon_{0} \chi^{e}\right)^{-1} d H ; \varepsilon_{0}$ is vacuum permeability; $\chi^{e}$ is electrical susceptibility.

Finding the right material for a magnetocaloric refrigerator is only a part of the task, since there is a need to generate large variable magnetic fields (with amplitudes up to several Tesla). Without water-cooled solenoids or superconducting magnets, which diminish the efficiency of the magnetocaloric cooling method, a variable magnetic field can be created by a mechanical motion of permanent magnets relative to the active caloric material. Motion produces noise and friction, resulting in wear and tear of the moving parts.

There was a suggestion [328] to avoiding such problems by using artificial magnetoelectric materials and multiferroics. According to [328], the magnetic properties of the material can be controlled using the electrical voltage applied to the piezoelectric layer rigidly bonded to the magnetic material. A multicaloric device exploits the synergistic effect that occurs in an interconnected system and amplifies the resulting caloric effect.

In general, transition temperature $T_{\mathcal{c}}$ of a magnetostructural [329] or magneto-volume phase transition depends on external magnetic field, stress, and strain. Response of a caloric material to one physical field does not disallow response to others. Thus, many caloric materials are multicaloric [330]. Multicaloric materials and effects are extensively studied nowadays [331,332].

\subsubsection{Hysteresis}

Most of the materials with a giant MCE undergo a first-order phase transition, whose latent heat contributes to the amplitude of the caloric effect in these materials. Hysteresis is a common feature of the first-order phase transitions [333]. A large thermomagnetic hysteresis results in an energy loss, released as a parasitic heat, which limits the usability of materials for caloric cooling [3]. Hysteresis is increased by nucleation barriers, activation energy, and strain due to a lattice misfit [334]. For structural transformations in solids, there is a connection between the hysteresis width and the middle eigenvalue $\lambda_{2}$ of the transformation stretch matrix $[333,334]$. Hysteresis is a rather well studied phenomenon: its causes and the ways to overcome negative consequences are described in the review [335]. A negligible hysteresis was observed at the first-order magnetic transitions in $\mathrm{Eu}_{2} \operatorname{In}$ [140] and $\operatorname{Pr}_{2} \operatorname{In}$ [336] line compounds. However, not only the hysteresis, but also aging due to cycling in a changing magnetic field affects the amplitude $\Delta T$ of the magnetocaloric response [24,337].

\subsubsection{Aging}

The phenomenon of a reduction of MCE with cycling is called aging. Let us consider aging in the FeRh alloys that manifest a negative magnetocaloric effect with a maximum near room temperature [21-24], see Figure 5a,b. Typical experimental curves $\Delta T(H)$ are presented in Figure 3 in [337]. In addition to the field hysteresis (e.g., 1.2 Tesla in Figure 5b), there is an irreversible trajectory: the sample temperature does not return to the initial value after one full cycle of the changing magnetic field. This aging effect is observed at all temperatures in the range of $300-340 \mathrm{~K}$, and its value depends on $T$, see Figure 4 in [337]. The maximum of this effect is shifted by $\sim 2 \mathrm{~K}$ compared to the peak of 
$\Delta T(T)$ curve. The value of $\Delta T$ in FeRh is large in the first cycle, but becomes smaller in the subsequent cycles, see Figure $5 \mathrm{~b}$. In the $\mathrm{Fe}_{50.4} \mathrm{Rh}_{49.6}$ sample, $\Delta T$ changes from $\Delta T_{1}=-7.5 \mathrm{~K}$ in the first cycle to $\Delta T_{2}=-3.4 \mathrm{~K}$ in the second one [337]. Aging is observed in many magnetocaloric materials that experience the first-order phase transition during work cycles [335].
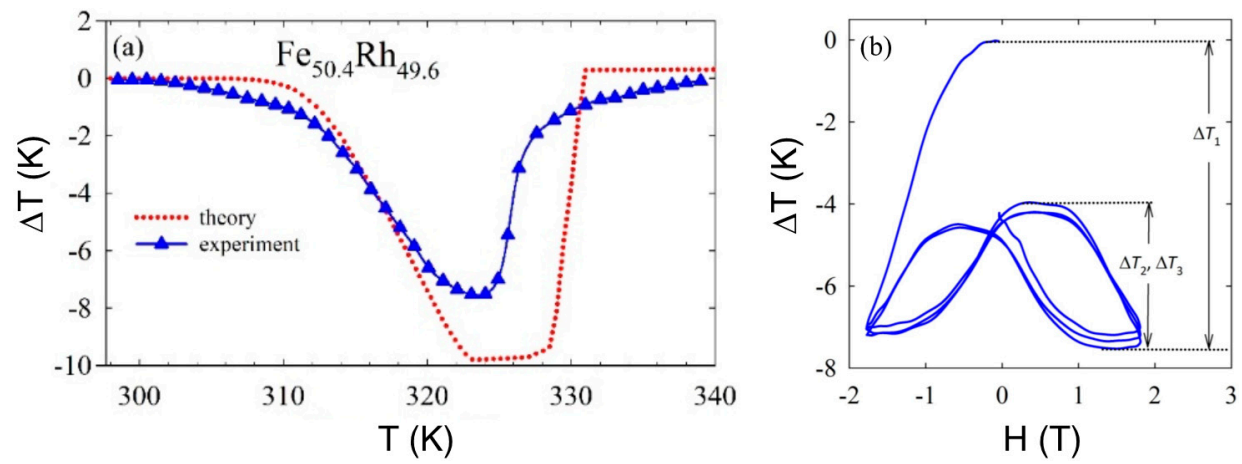

Figure 5. (a) Theoretical and experimental $\Delta T(T)$ at 1.8 Tesla for the first magnetic field cycle $(H=0 \rightarrow+1.8$ $\mathrm{T} \rightarrow 0 \rightarrow-1.8 \mathrm{~T} \rightarrow 0$ ) versus initial temperature $T$, and $(\mathbf{b})$ experimental $\Delta T(H)$ at $324 \mathrm{~K}$ for three cycles of magnetization/demagnetization in the $\mathrm{Fe}_{50.4} \mathrm{Rh}_{49.6}$ sample. Data is from [337].

From a practical point of view, together with hysteresis, aging lowers cooling efficiency in magnetic refrigerators using multistage magnetization/demagnetization cycles. Thus, the elucidation of the origin of irreversibility during the first cooling cycle and a drop of MCE during subsequent cycles may lead to discovery of new materials that retain their magnetocaloric properties during cycling.

\subsection{Materials Life Cycle and Recyclability}

Currently, most of materials are moved irreversibly from the natural resources to landfills (Figure 6). This consumption of natural resources is not sustainable and results in accumulation of waste. Material discovery alters waste compositions, while wasteless technologies are still needed.

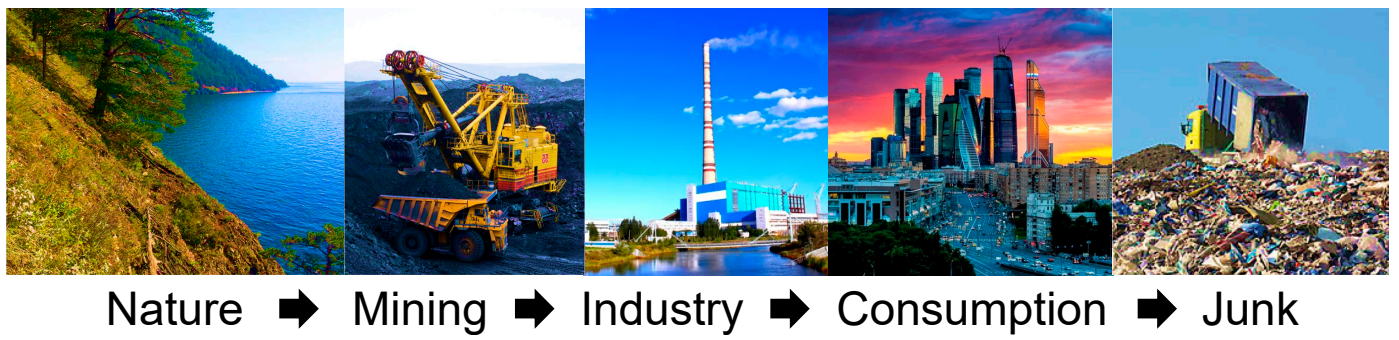

Figure 6. How mankind moves materials. Natural resources are shrinking; demand and consumption are increasing; landfills are growing; water and atmosphere are polluted. Images: Baikal lake; coal mining in Kuznetsk basin (Kuzbass); Ekibastuz GRES-2 power plant with 420-m chimney; Moscow city; a landfill. Images are from the open sources.

The explosive growth of materials research results not only in the rapid increase of the number of useful materials, but also in a substantial broadening of the spectrum of their practical applications. In magnetocalorics, along with the traditional technologies for obtaining ultra-low temperatures and magnetic cooling, the biomedical applications come to the fore: the method of magneto-liquid hyperthermia treatment of malignant neoplasms and a targeted drug delivery $[300,338]$. However, products have their lifetime, at the end of which they need to be disposed of [339].

Life cycle of caloric materials includes extraction of elements, materials synthesis, manufacturing and assembly into a device, packaging and transportation, followed by storage, use, and disposal together with the device. After disposal, the disassembly of a device into individual components and 
their recycling is preferred for precious and high-cost materials. However, the cost of the magnetocaloric materials lowers with time; this makes them more suitable for mass production, but less attractive for recycling, which requires disassembly of disposed items. Most of the magnetocaloric materials are synthesized from high-purity ingredients, because a phase transition temperature and hysteresis width are highly sensitive to impurities. Reuse of old low-purity materials for synthesis of new high-purity ones is diminished due to high cost of purification.

There are established recycling methods for structural and scrap metals, magnets, and batteries. There was a suggestion of a separate recycling for materials containing critical elements, such as metallic $\mathrm{Gd}$ and rare earth compounds $\left(\mathrm{Gd}_{5} \mathrm{Si}_{2} \mathrm{Ge}\right)$. However, those materials are being replaced by others, composed by more abundant elements. A separate recycling of magnetocaloric materials is problematic due to a rapid change of compositions of the best-in-class materials, purity constraints, and a relatively low market share. Due to a diversity of magnetocaloric materials, there is no single recycling technique that fits them all. For example, precious FeRh and toxic MnAs require different handling methods and should not be mixed during recycling. Non-toxic caloric materials (such as $\mathrm{Ni}_{37.5} \mathrm{Co}_{12.5} \mathrm{Mn}_{35} \mathrm{Ti}_{15}$ ) contain metals and can be recycled together with metals.

\section{Summary}

The correlation between elemental abundance and mass production provides constraints on chemical compositions of materials, viable for industry. Cost is an important economic factor. Toxicity affects the cost of handling during the whole life cycle of materials and products. Properties of materials depend on composition, structure, atomic ordering, heat treatment, applied fields, and external conditions. For magnetocalorics, important properties include the MCE, hysteresis, aging, recyclability, toxicity, and cost. We considered the caloric effect and its correlations with other physical properties. A magnetocaloric effect is useful for energy transformations, with applications in refrigeration, heat pumping, and energy generation. There is a vast literature on magnetocalorics. We focused on the economically viable materials with a giant MCE near room temperature. We pointed at the best-in-class materials and constructed a timeline (see Figure 2). Diversity among the known magnetocaloric materials increases with time. Recent observation [30,31] of a giant MCE in materials composed by abundant and non-toxic chemical elements can become a game changer in commercial applications of magnetocalorics.

Author Contributions: N.A.Z. prepared the original draft and wrote Sections 1, 2 and 4. V.I.Z. wrote most of Section 3. Both authors have agreed to publish. All authors have read and agreed to the published version of the manuscript.

Funding: Basic research at the Ames Laboratory is funded by the U.S. Department of Energy (DOE), Office of Science, Basic Energy Sciences, Materials Science and Engineering Division. Caloric materials discovery is supported by the U.S. DOE, Advanced Manufacturing Office of the Office of Energy Efficiency and Renewable Energy through CaloriCool ${ }^{\mathrm{TM}}$-the Caloric Materials Consortium established as a part of the U.S. DOE Energy Materials Network. Ames Laboratory is operated for the U.S. DOE by Iowa State University under contract DE-AC02-07CH11358.

Acknowledgments: Anis Biswas, Yaroslav Mudryk, Andrey Smirnov, Duane D. Johnson, and Vitalij K. Pecharsky are cordially acknowledged for discussions.

Conflicts of Interest: The authors declare no conflict of interest. Opinion of the authors does not represent opinions of any governmental organizations.

\section{References}

1. Zarkevich, N.A. Electricity without Fuel. J. Energy Power Technol. 2020, 2, 14. [CrossRef]

2. U.S. Department of Energy. 2020. Available online: https://www.energy.gov/ (accessed on 6 June 2020).

3. CaloriCool. Caloric Materials Consortium. 2020. Available online: https://www.caloricool.org/ (accessed on 6 June 2020).

4. Kitanovski, A. Energy Applications of Magnetocaloric Materials. Adv. Energy Mater. 2020, 10, 1903741. [CrossRef] 
5. Tishin, A.M.; Spichkin, Y.I. The Magnetocaloric Effect and Its Applications; Series in Condensed Matter Physics; Philadelphia: Institute of Physics Pub: Bristol, UK, 2003; Volume xi, 475p.

6. Magnetocaloric Energy Conversion; Springer: New York, NY, USA, 2014.

7. Mozharivskyj, Y. Magnetocaloric Effect and Magnetocaloric Materials. In Reference Module in Chemistry, Molecular Sciences and Chemical Engineering; Elsevier: Amsterdam, The Netherlands, 2016.

8. Gschneidner, K.A.; Pecharsky, V.K. Magnetic Refrigeration. In Rare Earths: Science, Technology E Applications iii; TMS: Beijing, China, 1996; Volume 3, pp. 209-221, ISBN $0873393635 / 9780873393638$.

9. Gschneidner, K.A.; Pecharsky, V.K.; Pecharsky, A.O.; Zimm, C.B. Recent developments in magnetic refrigeration. Mater. Sci. Forum 1999, 315, 69-76. [CrossRef]

10. Pecharsky, V.K.; Gschneidner, K.A. Magnetocaloric effect and magnetic refrigeration. J. Magn. Magn. Mater. 1999, 200, 44-56. [CrossRef]

11. Tishin, A.M.; Gschneidner, K.A.; Pecharsky, V.K. Magnetocaloric effect and heat capacity in the phase-transition region. Phys. Rev. B 1999, 59, 503-511. [CrossRef]

12. Gschneidner, K.A.; Pecharsky, V.K. Magnetocaloric materials. Annu. Rev. Mater. Sci. 2000, 30, 387-429. [CrossRef]

13. Tassou, S.A.; Lewis, J.S.; Ge, Y.T.; Hadawey, A. A review of emerging technologies for food refrigeration applications. Appl. Therm. Eng. 2010, 30, 263-276. [CrossRef]

14. Pomeranchuk, I.Y. К теории жидкого He-3. Sov. Phys. JETP (USSR) 1950, 20, 919.

15. Pomeranchuk, I.Y. Sobranie Nauchnykh Trudov. V 3-kh T; Nauka: Moskva, Russia, 1972; Volume 1.

16. Greco, A.; Aprea, C.; Maiorino, A.; Masselli, C. A review of the state of the art of solid-state caloric cooling processes at room-temperature before 2019. Int. J. Refrigeration 2019, 106, 66-88. [CrossRef]

17. Klinar, K.; Kitanovski, A. Thermal control elements for caloric energy conversion. Renew. Sustain. Energy Rev. 2020, 118, 109571. [CrossRef]

18. Tesla, N. Pyromagneto-Electric Generator. U.S. Patent No. 428,057, 13 May 1890.

19. Zarkevich, N.A.; Johnson, D.D. Reliable thermodynamic estimators for screening caloric materials. J. Alloys Compd. 2019, 802, 712-722. [CrossRef]

20. Ponomarev, B.K. Investigation of the antiferro-ferromagnetism transition in an FeRh alloy in a pulsed magnetic field up to 300 koe. Sov. Phys. JETP (USSR) 1973, 36, 105.

21. Nikitin, S.; Skokov, K.P.; Koshkid'ko, Y.S.; Pastushenkov, Y.G.; Ivanova, T.I. The magnetocaloric effect in $\mathrm{Fe}_{49} \mathrm{Rh}_{51}$ compound. Phys. Lett. 1990, 6-7, 363-366. [CrossRef]

22. Annaorazov, M.P.; Nikitin, S.A.; Tyurin, A.L.; Asatryan, K.A.; Dovletov, A.K. Anomalously high entropy change in FeRh alloy. J. Appl. Phys. 1996, 79, 1689-1695. [CrossRef]

23. Sanchez-Valdes, C.F.; Gimaev, R.R.; Lopez-Cruz, M.; Llamazares, J.L.S.; Zverev, V.I.; Tishin, A.M.; Carvalho, A.M.G.; Aguiar, D.J.M.; Mudryk, Y.; Pecharsky, V.K. The effect of cooling rate on magnetothermal properties of $\mathrm{Fe}_{49} \mathrm{Rh}_{51}$. J. Magn. Magn. Mater. 2020, 498, 166130. [CrossRef]

24. Chirkova, A.; Skokov, K.P.; Schultz, L.; Baranov, N.V.; Gutfleisch, O.; Woodcock, T.G. Giant adiabatic temperature change in FeRh alloys evidenced by direct measurements under cyclic conditions. Acta Mater. 2016, 106, 15-21. [CrossRef]

25. Zakharov, A.I.; Kadomtseva, A.M.; Levitin, R.Z.; Ponyatovskii, E.G. Magnetic and magnetoelastic properties of a metamagnetic iron-rhodium alloy. Sov. Phys. JETP (USSR) 1964, 19, 1348.

26. Shirane, G.; Nathans, R.; Chen, C.W. Magnetic moments and unpaired spin densities in the Fe-Rh alloys. Phys. Rev. 1964, 134, A1547-A1553. [CrossRef]

27. Brown, G.V. Magnetic heat pumping near room temperature. J. Appl. Phys. 1976, 47, 3673-3680. [CrossRef]

28. Pecharsky, V.K.; Gschneidner, J.K.A. Giant Magnetocaloric Effect in $\mathrm{Gd}_{5} \mathrm{Si}_{2} \mathrm{Ge}_{2}$. Phys. Rev. Lett. 1997, 78, 4494-4497. [CrossRef]

29. Zarkevich, N.A.; Johnson, D.D.; Pecharsky, V.K. High-throughput search for caloric materials: The CaloriCool approach. J. Phys. D Appl. Phys. 2017, 51, 024002. [CrossRef]

30. Bez, H.N.; Pathak, A.K.; Biswas, A.; Zarkevich, N.A.; Balema, V.; Mudryk, Y.; Johnson, D.D.; Pecharsky, V.K. Giant enhancement of the magnetocaloric response in $\mathrm{Ni}-\mathrm{Co}-\mathrm{Mn}-\mathrm{Ti}$ by rapid solidification. Acta Mater. 2019, 173, 225-230.

31. Biswas, A.; Pathak, A.K.; Zarkevich, N.A.; Liu, X.; Mudryk, Y.; Balema, V.; Johnson, D.D.; Pecharsky, V.K. Designed materials with the giant magnetocaloric effect near room temperature. Acta Mater. 2019, 180,341-348. [CrossRef] 
32. Zarkevich, N.A.; Johnson, D.D. FeRh ground state and martensitic transformation. Phys. Rev. B 2018, 97, 014202. [CrossRef]

33. Yibole, H.; Pathak, A.K.; Mudryk, Y.; Guillou, F.; Zarkevich, N.A.; Gupta, S.; Balema, V.; Pecharsky, V.K. Manipulating the stability of crystallographic and magnetic sub-lattices: A first-order magnetoelastic transformation in transition metal based Laves phase. Acta Mater. 2018, 154, 365-374. [CrossRef]

34. Bez, H.N.; Biswas, A.; Pathak, A.K.; Mudryk, Y.; Zarkevich, N.A.; Balema, V.; Pecharsky, V.K. Highly Tunable, Inexpensive and Easily Fabricated Magnetocaloric Materials; Iowa State University Research Foundation: Ames, IA, USA, 2019; U.S. Patent Application No. 2019/0214169A1, 11 July 2019.

35. Pathak, A.K.; Mudryk, Y.; Dolotko, O.; Pecharsky, V.K. Modified La-Fe-Si Magnetocaloric Alloys; Iowa State University Research Foundation: Ames, IA, USA, 2019; U.S. Patent Application No. US2019/027293A1, 5 September 2019.

36. Gschneidner, K.A.; Pecharsky, V.K. Thirty years of near room temperature magnetic cooling: Where we are today and future prospects. Int. J. Refrig. 2008, 31, 945-961. [CrossRef]

37. Dan'kov, S.Y.; Tishin, A.M.; Pecharsky, V.K.; Gschneidner, K.A. Experimental device for studying the magnetocaloric effect in pulse magnetic fields. Rev. Sci. Instrum. 1997, 68, 2432-2437. [CrossRef]

38. Dan'kov, S.Y.; Tishin, A.M.; Pecharsky, V.K.; Gschneidner, K.A. Magnetic phase transitions and the magnetothermal properties of gadolinium. Phys. Rev. B 1998, 57, 3478-3490. [CrossRef]

39. Dong, Q.Y.; Hou, K.Y.; Zhang, X.Q.; Su, L.; Wang, L.C.; Ke, Y.J.; Yan, H.T.; Cheng, Z.H. Giant reversible magnetocaloric effect in antiferromagnetic rare-earth cobaltite $\mathrm{GdCoO}_{3}$. J. Appl. Phys. 2020, 127, 033904. [CrossRef]

40. Pecharsky, V.K.; Gschneidner, K.A.; Dan'kov, S.Y.; Tishin, A.M. Magnetocaloric properties of $\mathrm{Gd}_{3} \mathrm{Al}_{2}$. In Cryocoolers 10; Springer: Boston, MA, USA, 1999; pp. 639-645, ISBN: 030646120X/030646090X.

41. Pecharsky, V.K.; Gschneidner, K.A. Gd-Zn alloys as active magnetic regenerator materials for magnetic refrigeration. In Cryocoolers 10; Springer: Boston, MA, USA, 1999; pp. 629-637, ISBN: 030646120X/030646090X.

42. Liu, J.; Gong, Y.Y.; Xu, G.Z.; Peng, G.; Shah, I.A.; Hassan, N.; Xu, F. Realization of magnetostructural coupling by modifying structural transitions in MnNiSi-CoNiGe system with a wide Curie-temperature window. Sci. Rep. 2016, 6, 23386. [CrossRef]

43. Samanta, T.; Dubenko, I.; Quetz, A.; Stadler, S.; Ali, N. Giant magnetocaloric effects near room temperature in $\mathrm{Mn}_{1-\mathrm{x}} \mathrm{Cu}_{\mathrm{x}} \mathrm{CoGe}$. Appl. Phys. Lett. 2012, 101, 242405. [CrossRef]

44. Zhou, X.Z.; Li, W.; Kunkel, H.P.; Williams, G. A criterion for enhancing the giant magnetocaloric effect: (Ni-Mn-Ga)—A promising new system for magnetic refrigeration. J. Phys.-Condens. Matter 2004, 16, L39-L44. [CrossRef]

45. Wada, H.; Tanabe, Y. Giant magnetocaloric effect of MnAs ${ }_{1-x} \mathrm{Sb}_{\mathrm{x}}$. Appl. Phys. Lett. 2001, 79, 3302-3304. [CrossRef]

46. Wada, H.; Tanabe, Y. Giant magnetocaloric effect of $\mathrm{MnAs}_{1-\mathrm{x}} \mathrm{Sb}_{\mathrm{x}}$ in the vicinity of first-order magnetic transition. Phys. B-Condens. Matter 2003, 328, 114-116. [CrossRef]

47. von Ranke, P.J.; de Oliveira, N.A.; Gama, S. Theoretical investigations on giant magnetocaloric effect in $\mathrm{MnAs}_{1-\mathrm{x}} \mathrm{Sb}_{\mathrm{x}}$. Phys. Lett. A 2004, 320, 302-306. [CrossRef]

48. von Ranke, P.J.; de Campos, A.; Caron, L.; Coelho, A.A.; Gama, S.; de Oliveira, N.A. Calculation of the giant magnetocaloric effect in the $\mathrm{MnFeP}_{0.45} \mathrm{As}_{0.55}$ compound. Phys. Rev. B 2004, 70, 094410. [CrossRef]

49. Xiao, S.F.; Chen, Y.G.; Tu, M.J. Introduction to a new kind of magnetic refrigerating material with giant magnetocaloric effect-Mn-Fe-P-As compounds. Rare Met. Mater. Eng. 2004, 33, 23-28.

50. Zhang, Y.Q.; Zhang, Z.D. Giant magnetoresistance and magnetocaloric effects of the $\mathrm{Mn}_{1.82} \mathrm{~V}_{0.18} \mathrm{Sb}$ compound. J. Alloys Compd. 2004, 365, 35-38. [CrossRef]

51. Kartashev, A.V.; Flerov, I.N.; Gorev, M.V.; Mikhashenok, N.V. Effect of Isovalent Cation Substitution on the Thermal, Caloric, and Magnetocaloric Properties of the $\left(\mathrm{La}_{1-y} \mathrm{Eu}_{\mathrm{y}}\right)_{0.7} \mathrm{~Pb}_{0.3} \mathrm{MnO}_{3}$ Manganites. Phys. Solid State 2019, 61, 62-68. [CrossRef]

52. Fujita, A.; Fujieda, S.; Hasegawa, Y.; Fukamichi, K. Itinerant-electron metamagnetic transition and large magnetocaloric effects in $\mathrm{La}\left(\mathrm{Fe}_{\mathrm{x}} \mathrm{Si}_{1-\mathrm{x}}\right)_{13}$ compounds and their hydrides. Phys. Rev. B 2003, 67, 104416. [CrossRef]

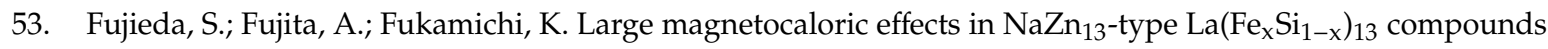
and their hydrides composed of icosahedral clusters. Sci. Technol. Adv. Mater. 2003, 4, 339-346. [CrossRef] 
54. Terwey, A.; Gruner, M.E.; Keune, W.; Landers, J.; Salamon, S.; Eggert, B.; Ollefs, K.; Brabander, V.; Radulov, I.; Skokov, K.; et al. Influence of hydrogenation on the vibrational density of states of magnetocaloric $\mathrm{LaFe}_{11.4} \mathrm{Si}_{1.6} \mathrm{H}_{1.6}$. Phys. Rev. B 2020, 101, 064415. [CrossRef]

55. Debnath, J.C.; Zeng, R.; Kim, J.H.; Shamba, P.; Dou, S.X. Reduction of hysteresis loss in $\operatorname{LaFe}_{11.7} \mathrm{Si}_{1.3} \mathrm{H}_{\mathrm{x}}$ hydrides with significant magnetocaloric effects. Appl. Phys. A 2012, 106, 245-250. [CrossRef]

56. Pecharsky, V.K.; Gschneidner, K.A. Effect of alloying on the giant magnetocaloric effect of $\mathrm{Gd}_{5}\left(\mathrm{Si}_{2} \mathrm{Ge}_{2}\right)$. J. Magn. Magn. Mater. 1997, 167, L179-L184. [CrossRef]

57. Pecharsky, V.K.; Gschneidner, K.A. Tunable magnetic regenerator alloys with a giant magnetocaloric effect for magnetic refrigeration from $\sim 20$ to $290 \mathrm{~K}$. Appl. Phys. Lett. 1997, 70, 3299-3301. [CrossRef]

58. Pecharsky, V.K.; Gschneidner, K.A. The giant magnetocaloric effect in $\mathrm{Gd}_{5}\left(\mathrm{Si}_{\mathrm{x}} \mathrm{Ge}_{1-\mathrm{x}}\right)_{4}$ materials for magnetic refrigeration. Adv. Cryog. Eng. 1998, 43 (Pts A and B), 1729-1736.

59. Giguere, A.; Foldeaki, M.; Gopal, B.R.; Chahine, R.; Bose, T.K.; Frydman, A.; Barclay, J.A. Direct measurement of the "giant" adiabatic temperature change in $\mathrm{Gd}_{5} \mathrm{Si}_{2} \mathrm{Ge}_{2}$. Phys. Rev. Lett. 1999, 83, 2262-2265. [CrossRef]

60. Gschneidner, K.A.; Pecharsky, A.O.; Pecharsky, V.K.; Lograsso, T.A.; Schlagel, D.L. Production of the giant magnetocaloric effect $\mathrm{Gd}_{5}\left(\mathrm{Si}_{\mathrm{x}} \mathrm{Ge}_{1-\mathrm{x}}\right)_{4}$ magnetic refrigerant materials from commercial gadolinium metal. In Rare Earths and Actinides: Science, Technology and Applications IV: Proceedings of a Symposium Held During the 2000 TMS Annual Meeting in Nashville, Nashville, TN, USA, 12-16 March 2000; TMS: Beijing, China, 2000; pp. 63-72, ISBN: 0873394704.

61. Choe, W.; Pecharsky, V.K.; Pecharsky, A.O.; Gschneidner, K.A.; Young, V.G.; Miller, G.J. Making and breaking covalent bonds across the magnetic transition in the giant magnetocaloric material $\mathrm{Gd}_{5}\left(\mathrm{Si}_{2} \mathrm{Ge}_{2}\right)$. Phys. Rev. Lett. 2000, 84, 4617-4620. [CrossRef]

62. Pecharsky, A.O.; Gschneidner, K.A.; Pecharsky, V.K. The giant magnetocaloric effect between 190 and $300 \mathrm{~K}$ in the $\mathrm{Gd}_{5} \mathrm{Si}_{\mathrm{x}} \mathrm{Ge}_{4-\mathrm{x}}$ alloys for $1.4<=\mathrm{x}<=2.2$. J. Magn. Magn. Mater. 2003, 267, 60-68.

63. Pecharsky, A.O.; Gschneidner, K.A., Jr.; Pecharsky, V.K. The giant magnetocaloric effect of optimally prepared $\mathrm{Gd}_{5} \mathrm{Si}_{2} \mathrm{Ge}_{2}$. J. Appl. Phys. 2003, 93, 4722-4728. [CrossRef]

64. Casanova, F.; Batlle, X.; Labarta, A.; Marcos, J.; Manosa, L.; Planes, A. Change in entropy at a first-order magnetoelastic phase transition: Case study of $\mathrm{Gd}_{5}\left(\mathrm{Si}_{\mathrm{x}} \mathrm{Ge}_{1-\mathrm{x}}\right)_{4}$ giant magnetocaloric alloys. J. Appl. Phys. 2003, 93, 8313-8315. [CrossRef]

65. Lewis, L.H.; Yu, M.H.; Gambino, R.J. Simple enhancement of the magnetocaloric effect in giant magnetocaloric materials. Appl. Phys. Lett. 2003, 83, 515-517. [CrossRef]

66. Wu, W.; Zhao, P.; Jiang, Z.L.; Li, Y.H.; Zhu, X.D.; Zhou, T.D. Influence of Gd purity on giant magnetocaloric effect of Gd-Si-Ge alloys. Rare Met. Mater. Eng. 2003, 32, 962-964.

67. Casanova, F.; Labarta, A.; Batlle, X.; Perez-Reche, F.J.; Vives, E.; Manosa, L.; Planes, A. Direct observation of the magnetic-field-induced entropy change in $\mathrm{Gd}_{5}\left(\mathrm{Si}_{x} \mathrm{Ge}_{1-\mathrm{x}}\right)_{4}$ giant magnetocaloric alloys. Appl. Phys. Lett. 2005, 86, 262504. [CrossRef]

68. Wu, W.; Tsokol, A.O.; Gschneidner, K.A.; Sampaio, J.A. Influence of oxygen on the giant magnetocaloric effect of $\mathrm{Gd}_{5} \mathrm{Si}_{1.95} \mathrm{Ge}_{2.05}$. J. Alloys Compd. 2005, 403, 118-123. [CrossRef]

69. Pecharsky, V.K.; Holm, A.P.; Gschneidner, K.A.; Rink, R. Massive magnetic-field-induced structural transformation in $\mathrm{Gd}_{5} \mathrm{Ge}_{4}$ and the nature of the giant magnetocaloric effect. Phys. Rev. Lett. 2003, 91, 197204. [CrossRef]

70. Magen, C.; Arnold, Z.; Morellon, L.; Skorokhod, Y.; Algarabel, P.A.; Ibarra, M.R.; Kamarad, J. Pressure-induced three-dimensional ferromagnetic correlations in the giant magnetocaloric compound $\mathrm{Gd}_{5} \mathrm{Ge}_{4}$. Phys. Rev. Lett. 2003, 91, 207202. [CrossRef]

71. Ryan, D.H.; Wang, H.B.; Altounian, Z. Sn-119 Mossbauer study of the giant magnetocaloric compound: $\mathrm{Gd}_{5} \mathrm{Sn}_{4}$. In Hyperfine Interactions (C): Proceedings of the International Conference on the Applications of the Mössbauer Effect (ICAME 2001); Kluwer: Oxford, UK, 2002; Volume 5, pp. 217-220.

72. Ryan, D.H.; Elouneg-Jamroz, M.; van Lierop, J.; Altounian, Z.; Wang, H.B. Field and temperature induced magnetic transition in $\mathrm{Gd}_{5} \mathrm{Sn}_{4}$ : A giant magnetocaloric material. Phys. Rev. Lett. 2003, 90, 117202. [CrossRef]

73. Morellon, L.; Arnold, Z.; Magen, C.; Ritter, C.; Prokhnenko, O.; Skorokhod, Y.; Algarabel, P.A.; Ibarra, M.R.; Kamarad, J. Pressure enhancement of the giant magnetocaloric effect in $\mathrm{Tb}_{5} \mathrm{Si}_{2} \mathrm{Ge}_{2}$. Phys. Rev. Lett. 2004, 93, 137201. [CrossRef]

74. Pasquale, M.; Sasso, C.P.; Lewis, L.H.; Giudici, L.; Lograsso, T.; Schlagel, D. Magnetostructural transition and magnetocaloric effect in $\mathrm{Ni}_{55} \mathrm{Mn}_{20} \mathrm{Ga}_{25}$ single crystals. Phys. Rev. B 2005, 72, 094435. [CrossRef] 
75. Wada, H.; Asano, T. Effect of heat treatment on giant magnetocaloric properties of $\mathrm{Mn}_{1+\delta} \mathrm{As}_{1-\mathrm{x}} \mathrm{Sb}_{\mathrm{x}} . J . \mathrm{Magn}$. Magn. Mater. 2005, 290, 703-705. [CrossRef]

76. Abramovich, A.I.; Michurin, A.V.; Gorbenko, O.Y.; Kaul', A.R. Giant magnetocaloric effect near the Curie temperature in the $\mathrm{Sm}_{0.6} \mathrm{Sr}_{0.4} \mathrm{MnO}_{3}$ manganite. Phys. Solid State 2001, 43, 715-717. [CrossRef]

77. Yamada, H.; Goto, T. Itinerant-electron metamagnetism and giant magnetocaloric effect. Phys. Rev. B 2003, 68, 184417. [CrossRef]

78. Yamada, H.; Goto, T. Giant magnetocaloric effect in itinerant-electron metamagnets. Phys. B-Condens. Matter 2004, 346, 104-108. [CrossRef]

79. de Oliveira, I.G.; von Ranke, P.J.; El Massalami, M.; Chaves, C.M. Giant magnetocaloric effect in tetragonal $\mathrm{HoNi}_{2} \mathrm{~B}_{2}$ C. Phys. Rev. B 2005, 72, 174420. [CrossRef]

80. Yan, J.L.; Li, Z.Z.; Chen, X.; Zhou, K.W.; Shen, S.X.; Zhou, H.B. Martensitic transition and magnetocaloric properties in $\mathrm{Ni}_{45} \mathrm{Mn}_{44-\mathrm{x}} \mathrm{Fe}_{\mathrm{x}} \mathrm{Sn}_{11}$ alloys. J. Alloys Compd. 2010, 506, 516-519. [CrossRef]

81. Gottschall, T.; Skokov, K.P.; Burriel, R.; Gutfleisch, O. On the S(T) diagram of magnetocaloric materials with first-order transition: Kinetic and cyclic effects of Heusler alloys. Acta Mater. 2016, 107, 1-8. [CrossRef]

82. Gottschall, T.; Skokov, K.P.; Frincu, B.; Gutfleisch, O. Large reversible magnetocaloric effect in Ni-Mn-In-Co. Appl. Phys. Lett. 2015, 106, 021901. [CrossRef]

83. Gottschall, T.; Skokov, K.P.; Fries, M.; Taubel, A.; Radulov, I.; Scheibel, F.; Benke, D.; Riegg, S.; Gutfleisch, O. Making a Cool Choice: The Materials Library of Magnetic Refrigeration. Adv. Energy Mater. 2019, 9, 1901322. [CrossRef]

84. Medvedeva, I.V.; Ganin, A.A.; Shcherbakova, Y.V.; Yermolenko, A.S.; Bersenev, Y.S. Magnetic phase transitions in the system $\mathrm{La}(\mathrm{Fe}, \mathrm{Co}, \mathrm{Ai})_{13}$ at high pressures. J. Alloys Compd. 1992, 178, 403-412. [CrossRef]

85. Feng-Xia, H.; Bao-Gen, S.; Ji-Rong, S.; Xi-Xiang, Z. Great magnetic entropy change in $\mathrm{La}(\mathrm{Fe}, \mathrm{M})_{13}(\mathrm{M}=\mathrm{Si}, \mathrm{Al})$ with Co doping. Chin. Phys. 2000, 9, 550-553. [CrossRef]

86. Hu, F.X.; Shen, B.G.; Sun, J.R.; Cheng, Z.H.; Rao, G.H.; Zhang, X.X. Influence of negative lattice expansion and metamagnetic transition on magnetic entropy change in the compound LaFe11.4Si1.6. Appl. Phys. Lett. 2001, 78, 3675-3677. [CrossRef]

87. Shen, B.G.; Sun, J.R.; Hu, F.X.; Zhang, H.W.; Cheng, Z.H. Recent Progress in Exploring Magnetocaloric Materials. Adv. Mater. 2009, 21, 4545-4564. [CrossRef]

88. Ilyn, M.; Tishin, A.M.; Hu, F.; Gao, J.; Sun, J.R.; Shen, B.G. Magnetocaloric properties of the LaFe $\mathrm{H}_{11.7} \mathrm{Si}_{1.3}$ and $\mathrm{LaFe}_{11.2} \mathrm{Co}_{0.7} \mathrm{Si}_{1.1}$ systems. J. Magn. Magn. Mater. 2005, 290, 712-714. [CrossRef]

89. Hu, F.X.; Gao, J.; Qian, X.L.; Ilyn, M.; Tishin, A.M.; Sun, J.R.; Shen, B.G. Magnetocaloric effect in itinerant electron metamagnetic systems $\mathrm{La}\left(\mathrm{Fe}_{1-\mathrm{x}} \mathrm{Co}_{\mathrm{x}}\right)_{11.9} \mathrm{Si}_{1.1}$. J. Appl. Phys. 2005, 97, 10M303. [CrossRef]

90. Spichkin, Y.I.; Pecharsky, V.K.; Gschneidner, K.A. Preparation, crystal structure, magnetic and magnetothermal properties of $\left(\mathrm{Gd}_{\mathrm{x}} \mathrm{R}_{5-\mathrm{x}}\right) \mathrm{Si}_{4}$, where $\mathrm{R}=\mathrm{Pr}$ and $\mathrm{Tb}$, alloys. J. Appl. Phys. 2001, 89, 1738-1745. [CrossRef]

91. Gottschall, T.; Kuz'min, M.D.; Skokov, K.P.; Skourski, Y.; Fries, M.; Gutfleisch, O.; Zavareh, M.G.; Schlagel, D.L.; Mudryk, Y.; Pecharsky, V.; et al. Magnetocaloric effect of gadolinium in high magnetic fields. Phys. Rev. B 2019, 99, 134429. [CrossRef]

92. Nayak, A.K.; Suresh, K.G.; Nigam, A.K. Giant inverse magnetocaloric effect near room temperature in Co substituted NiMnSb Heusler alloys. J. Phys. D-Appl. Phys. 2009, 42, 035009. [CrossRef]

93. Entel, P.; Sokolovskiy, V.V.; Buchelnikov, V.D.; Ogura, M.; Gruner, M.E.; Grunebohm, A.; Comtesse, D.; Akai, H. The metamagnetic behavior and giant inverse magnetocaloric effect in Ni-Co-Mn-(Ga, In, Sn) Heusler alloys. J. Magn. Magn. Mater. 2015, 385, 193-197. [CrossRef]

94. Ren, J.; Li, H.W.; Feng, S.T.; Zhai, Q.J.; Fu, J.X.; Luo, Z.P.; Zheng, H.X. Giant magnetocaloric effect in a Heusler Mn50Ni40In10 unidirectional crystal. Intermetallics 2015, 65, 10-14. [CrossRef]

95. Paramanik, T.; Das, I. Near room temperature giant magnetocaloric effect and giant negative magnetoresistance in Co, Ga substituted Ni-Mn-In Heusler alloy. J. Alloys Compd. 2016, 654, 399-403. [CrossRef]

96. Quetz, A.; Koshkid'ko, Y.S.; Titov, I.; Rodionov, I.; Pandey, S.; Aryal, A.; Ibarra-Gaytan, P.J.; Prudnikov, V.; Granovsky, A.; Dubenko, I.; et al. Giant reversible inverse magnetocaloric effects in $\mathrm{Ni}_{50} \mathrm{Mn}_{35} \mathrm{In}_{15}$ Heusler alloys. J. Alloys Compd. 2016, 683, 139-142. [CrossRef]

97. Pandey, S.; Quetz, A.; Aryal, A.; Dubenko, I.; Blinov, M.; Rodionov, I.; Prudnikov, V.; Mazumdar, D.; Granovsky, A.; Stadler, S.; et al. Giant field-induced adiabatic temperature changes in In-based off-stoichiometric Heusler alloys. J. Appl. Phys. 2017, 121, 133901. [CrossRef] 
98. Pandey, S.; Quetz, A.; Aryal, A.; Dubenko, I.; Mazumdar, D.; Stadler, S.; Ali, N. Large Inverse Magnetocaloric Effects and Giant Magnetoresistance in Ni-Mn-Cr-Sn Heusler Alloys. Magnetochemistry 2017, 3, 3. [CrossRef]

99. Chabri, T.; Ghosh, A.; Nair, S.; Awasthi, A.M.; Venimadhav, A.; Nath, T.K. Effects of the thermal and magnetic paths on first order martensite transition of disordered Ni45Mn44Sn9In2 Heusler alloy exhibiting a giant magnetocaloric effect and magnetoresistance near room temperature. J. Phys. D-Appl. Phys. 2018, 51, 195001. [CrossRef]

100. Sokolovskiy, V.; Miroshkina, O.; Zagrebin, M.; Buchelnikov, V. Prediction of giant magnetocaloric effect in $\mathrm{Ni}_{40} \mathrm{Co}_{10} \mathrm{Mn}_{36} \mathrm{Al}_{14}$ Heusler alloys: An insight from ab initio and Monte Carlo calculations. J. Appl. Phys. 2020, 127, 163901. [CrossRef]

101. Liu, F.S.; Wang, Q.B.; Li, S.P.; Ao, W.Q.; Li, J.Q. The martensitic transition and magnetocaloric properties of $\mathrm{Ni}_{51} \mathrm{Mn}_{49-\mathrm{x}} \mathrm{Sn}_{\mathrm{x}}$. Phys. B-Condens. Matter 2013, 412, 74-78. [CrossRef]

102. Krenke, T.; Duman, E.; Acet, M.; Moya, X.; Manosa, L.; Planes, A. Effect of Co and Fe on the inverse magnetocaloric properties of Ni-Mn-Sn. J. Appl. Phys. 2007, 102, 033903. [CrossRef]

103. Pasquale, M.; Sasso, C.P.; Giudici, L.; Lograsso, T.; Schlagel, D. Field-driven structural phase transition and sign-switching magnetocaloric effect in Ni-Mn-Sn. Appl. Phys. Lett. 2007, 91, 131904. [CrossRef]

104. Phejar, M.; Paul-Boncour, V.; Bessais, L. Structural and magnetic properties of magnetocaloric $\mathrm{LaFe}_{13-\mathrm{x}} \mathrm{Si}_{\mathrm{x}}$ compounds synthesized by high energy ball-milling. Intermetallics 2010, 18, 2301-2307. [CrossRef]

105. Chen, Y.-F.; Wang, F.; Shen, B.-G.; Sun, J.-R.; Wang, G.-J.; Hu, F.-X.; Cheng, Z.-H.; Zhu, T. Effects of carbon on magnetic properties and magnetic entropy change of the LaFe11.5Si1.5 compound. J. Appl. Phys. 2003, 93, 6981-6983. [CrossRef]

106. Taskaev, S.V.; Kuz'min, M.D.; Skokov, K.P.; Karpenkov, D.Y.; Pellenen, A.P.; Buchelnikov, V.D.; Gutfleisch, O. Giant induced anisotropy ruins the magnetocaloric effect in gadolinium. J. Magn. Magn. Mater. 2013, 331, 33-36. [CrossRef]

107. Amaral, J.S.; Amaral, V.S. Disorder effects in giant magnetocaloric materials. Phys. Status Solidi A-Appl. Mater. Sci. 2014, 211, 971-974. [CrossRef]

108. Niknia, I.; Trevizoli, P.V.; Christiaanse, T.V.; Govindappa, P.; Teyber, R.; Rowe, A. Material screening metrics and optimal performance of an active magnetic regenerator. J. Appl. Phys. 2017, 121, 064902. [CrossRef]

109. Kavita, S.; Anusha, G.; Bhatt, P.; Suresh, V.; Vijay, R.; Sethupathi, K.; Gopalan, R. On the giant magnetocaloric and mechanical properties of Mn-Fe-P-Si-Ge alloy. J. Alloys Compd. 2020, 817, 153232. [CrossRef]

110. Jiang, W.H.; Mo, Z.J.; Luo, J.W.; Zheng, Z.X.; Lu, Q.J.; Liu, G.D.; Shen, J.; Li, L. Giant low-field magnetocaloric effect in $\mathrm{EuTi}_{1-\mathrm{x}} \mathrm{Nb}_{\mathrm{x}} \mathrm{O}_{3}(\mathrm{x}=0.05,0.1,0.15$, and 0.2) compounds. Chin. Phys. B 2020, 29, 037502. [CrossRef]

111. Hanggai, W.; Tegus, O.; Yibole, H.; Guillou, F. Structural and magnetic phase diagrams of $\mathrm{MnFe}_{0.6} \mathrm{Ni}_{0.4}(\mathrm{Si}, \mathrm{Ge})$ alloys and their giant magnetocaloric effect probed by heat capacity measurements. J. Magn. Magn. Mater. 2020, 494, 165785. [CrossRef]

112. Zhang, Y.K.; Guo, D.; Xu, H.; Ren, Z.M.; Wilde, G. Giant refrigerant capacity in equi-atomic HoErGdCuNi amorphous ribbons. J. Alloys Compd. 2019, 792, 180-184. [CrossRef]

113. Zhang, W.; Mo, Z.J.; Jiang, W.H.; Hao, Z.H.; Luo, J.W.; Cheng, R.J.; Liu, G.D.; Li, L.; Shen, J. Giant low-field magnetic refrigeration in $\mathrm{EuTi}_{1-x} \mathrm{Al}_{\mathrm{x}} \mathrm{O}_{3}(\mathrm{x}=0.05,0.1$ and 0.15) compounds. J. Magn. Magn. Mater. 2019, 492, 165684. [CrossRef]

114. Zhang, W.; Mo, Z.J.; Hao, Z.H.; Shen, J.; Luo, J.W.; Chang, R.J.; Li, L. Fe doping effect on $\mathrm{EuTiO}_{3}$ : The magnetic properties and giant magnetocaloric effect. Int. J. Appl. Ceram. Technol. 2019, 16, 1606-1611. [CrossRef]

115. Zhang, K.; Tan, C.L.; Zhao, W.B.; Guo, E.J.; Tian, X.H. Computation-Guided Design of Ni-Mn-Sn Ferromagnetic Shape Memory Alloy with Giant Magnetocaloric Effect and Excellent Mechanical Properties and High Working Temperature via Multielement Doping. ACS Appl. Mater. Interfaces 2019, 11,34827-34840. [CrossRef] [PubMed]

116. Zhang, C.L.; Nie, Y.G.; Shi, H.F.; Ye, E.J.; Han, Z.D.; Wang, D.H. Tuning magnetostructural transition and the associated giant magnetocaloric effect via thermal treatment in MnCoGe-based alloys. J. Magn. Magn. Mater. 2019, 469, 437-442. [CrossRef]

117. Wu, Y.D.; Chen, H.; Hua, J.Y.; Qin, Y.L.; Ma, X.H.; Wei, Y.Y.; Zi, Z.F. Giant reversible magnetocaloric effect in orthorhombic $\mathrm{GdScO}_{3}$. Ceram. Int. 2019, 45, 13094-13098. [CrossRef]

118. Wada, H.; Fukuda, K.; Ohnishi, T.; Soejima, K.; Otsubo, K.; Yamashita, K. Thermal conductivity of giant magnetocaloric Mn compounds. J. Alloys Compd. 2019, 785, 445-451. [CrossRef] 
119. Mo, Z.J.; Jiang, W.H.; Zhao, Y.; Hao, Z.H.; Zheng, Z.X.; Zhang, W.; Li, L.; Shen, J. Low-field induced giant magnetocaloric effect in $\mathrm{EuTi}_{1-\mathrm{x}} \mathrm{NixO}_{3}(\mathrm{x}=0.05,0.1)$ compounds. J. Magn. Magn. Mater. 2019, 477, 258-263. [CrossRef]

120. Lloveras, P.; Samanta, T.; Barrio, M.; Dubenko, I.; Ali, N.; Tamarit, J.L.; Stadler, S. Giant reversible barocaloric response of $(\mathrm{MnNiSi})_{1-\mathrm{x}}(\mathrm{FeCoGe})_{\mathrm{x}}(\mathrm{x}=0.39,0.40,0.41)$. APL Mater. 2019, 7, 061106.

121. Liu, J.; Gong, Y.Y.; You, Y.R.; You, X.M.; Huang, B.W.; Miao, X.F.; Xu, G.Z.; Xu, F.; Bruck, E. Giant reversible magnetocaloric effect in MnNiGe-based materials: Minimizing thermal hysteresis via crystallographic compatibility modulation. Acta Mater. 2019, 174, 450-458. [CrossRef]

122. Li, Z.B.; Dong, S.Y.; Li, Z.Z.; Yang, B.; Liu, F.; Sanchez-Valdes, C.F.; Llamazares, J.L.S.; Zhang, Y.D.; Esling, C.; Zhao, X.; et al. Giant low-field magnetocaloric effect in Si alloyed Ni-Co-Mn-In alloys. Scr. Mater. 2019, 159, 113-118. [CrossRef]

123. Koshkid'ko, Y.S.; Dilmieva, E.T.; Cwik, J.; Rogacki, K.; Kowalska, D.; Kamantsev, A.P.; Koledov, V.V.; Mashirov, A.V.; Shavrov, V.G.; Valkov, V.I.; et al. Giant reversible adiabatic temperature change and isothermal heat transfer of MnAs single crystals studied by direct method in high magnetic fields. J. Alloys Compd. 2019, 798, 810-819. [CrossRef]

124. Jia, J.H.; Ke, Y.J.; Zhang, X.X.; Wang, J.F.; Su, L.; Wu, Y.D.; Xia, Z.C. Giant magnetocaloric effect in the antiferromagnet $\mathrm{GdScO}_{3}$ single crystal. J. Alloys Compd. 2019, 803, 992-997. [CrossRef]

125. Hussain, R.; Cugini, F.; Baldini, S.; Porcari, G.; Amade, N.S.; Miao, X.F.; van Dijk, N.H.; Bruck, E.; Solzi, M.; De Renzi, R.; et al. Ubiquitous first-order transitions and site-selective vanishing of the magnetic moment in giant magnetocaloric MnFeSiP alloys detected by Mn-55 NMR. Phys. Rev. B 2019, 100, 104439. [CrossRef]

126. Hu, S.Y.; Miao, X.F.; Liu, J.; Ou, Z.Q.; Cong, M.Q.; Haschuluu, O.; Gong, Y.Y.; Qian, F.J.; You, Y.R.; Zhang, Y.J.; et al. Small hysteresis and giant magnetocaloric effect in $\mathrm{Nb}$-substituted $(\mathrm{Mn}, \mathrm{Fe})_{2}(\mathrm{P}, \mathrm{Si})$ alloys. Intermetallics 2019, 114, 106602. [CrossRef]

127. Bouhani, H.; Endichi, A.; Zaari, H.; Benyoussef, A.; Hamedoun, M.; Balli, M.; El Kenz, A.; Mounkachi, O. On the origin of the giant magnetocaloric effect in $\mathrm{HoMn}_{2} \mathrm{O}_{5}$ single crystals: First principles study and Monte Carlo simulations. Mater. Chem. Phys. 2019, 231, 366-371. [CrossRef]

128. Beckmann, C.; Ehrens, J.; Schnack, J. Rotational magnetocaloric effect of anisotropic giant-spin molecular magnets. J. Magn. Magn. Mater. 2019, 482, 113-119. [CrossRef]

129. ul Hassan, N.; Shah, I.A.; Liu, J.; Xu, G.Z.; Gong, Y.Y.; Miao, X.F.; Xu, F. Magnetostructural Coupling and Giant Magnetocaloric Effect in Off-Stoichiometric MnCoGe Alloys. J. Supercond. Nov. Magn. 2018, 31, 3809-3815. [CrossRef]

130. Polishchuk, D.M.; Tykhonenko-Polishchuk, Y.O.; Holmgren, E.; Kravets, A.F.; Tovstolytkin, A.I.; Korenivski, V. Giant magnetocaloric effect driven by indirect exchange in magnetic multilayers. Phys. Rev. Mater. 2018, 2, 114402. [CrossRef]

131. Pankratov, N.; Mitsiuk, V.; Vetcher, A.; Krokhotin, A.; Govor, G.; Nikitin, S. Giant magnetocaloric effect in composites based on polymeric matrix and manganese arsenide. Mosc. Int. Symp. Magn. (MISM 2017) EPJ Web Conf. 2018, 185, 05010. [CrossRef]

132. Moon, J.Y.; Kim, M.K.; Oh, D.G.; Kim, J.H.; Shin, H.J.; Choi, Y.J.; Lee, N. Anisotropic magnetic properties and giant rotating magnetocaloric effect in double-perovskite $\mathrm{Tb}_{2} \mathrm{CoMnO}_{6}$. Phys. Rev. B 2018, 98, 174424 . [CrossRef]

133. Mo, Z.J.; Sun, Q.L.; Shen, J.; Yang, M.; Li, Y.J.; Li, L.; Liu, G.D.; Tang, C.C.; Meng, F.B. Influences of La and Ce doping on giant magnetocaloric effect of EuTiO. Chin. Phys. B 2018, 27, 017501. [CrossRef]

134. Mo, Z.J.; Sun, Q.L.; Shen, J.; Wang, C.H.; Meng, F.B.; Zhang, M.H.; Huo, Y.; Li, L.; Liu, G.D. A giant magnetocaloric effect in $\mathrm{EuTi}_{0.875} \mathrm{Mn}_{0.125} \mathrm{O}_{3}$ compound. J. Alloys Compd. 2018, 753, 1-5. [CrossRef]

135. Mo, Z.J.; Sun, Q.L.; Han, S.; Zhao, Y.; Chen, X.; Li, L.; Liu, G.D.; Meng, F.B.; Shen, J. Effects of Mn-doping on the giant magnetocaloric effect of $\mathrm{EuTiO}_{3}$ compound. J. Magn. Magn. Mater. 2018, 456, 31-37. [CrossRef]

136. Li, Z.Z.; Li, Z.B.; Yang, B.; Zhao, X.; Zuo, L. Giant low-field magnetocaloric effect in a textured $\mathrm{Ni}_{45.3} \mathrm{Co}_{5.1} \mathrm{Mn}_{36.1} \mathrm{In}_{13.5}$ alloy. Scr. Mater. 2018, 151, 61-65. [CrossRef]

137. Landers, J.; Salamon, S.; Keune, W.; Gruner, M.E.; Krautz, M.; Zhao, J.; Hu, M.Y.; Toellner, T.S.; Alp, E.E.; Gutfleisch, O.; et al. Determining the vibrational entropy change in the giant magnetocaloric material $\mathrm{LaFe}_{11.6} \mathrm{Si}_{1.4}$ by nuclear resonant inelastic x-ray scattering. Phys. Rev. B 2018, 98, 024417.

138. Ke, Y.J.; Zhang, X.Q.; Wang, J.F.; Cheng, Z.H. Giant magnetic entropy change in gadolinium orthoferrite near liquid hydrogen temperature. J. Alloys Compd. 2018, 739, 897-900. [CrossRef] 
139. Hu, F.X.; Shen, F.R.; Hao, J.Z.; Liu, Y.; Wang, J.; Sun, J.R.; Shen, B.G. Negative Thermal Expansion in the Materials with Giant Magnetocaloric Effect. Front. Chem. 2018, 6, 438. [CrossRef]

140. Guillou, F.; Pathak, A.K.; Paudyal, D.; Mudryk, Y.; Wilhelm, F.; Rogalev, A.; Pecharsky, V.K. Non-hysteretic first-order phase transition with large latent heat and giant low-field magnetocaloric effect. Nat. Commun. 2018, 9, 1-9. [CrossRef]

141. Gao, T.; Wu, M.; Qi, N.N.; Zhou, T.; Luo, X.J.; Liu, Y.S.; Xu, K.; Marchenkov, V.V.; Dong, H.L.; Chen, Z.Q.; et al. Giant low field magnetocaloric effect and magnetostructural coupling in $\mathrm{MnCoGe}_{1-\mathrm{x}} \mathrm{In}_{\mathrm{x}}$ around room temperature. J. Alloys Compd. 2018, 753, 149-154. [CrossRef]

142. Deepak, K.; Ramanujan, R.V. Near room temperature giant magnetocaloric effect in $(\mathrm{MnNiSi})_{1-\mathrm{x}}\left(\mathrm{Fe}_{2} \mathrm{Ge}\right)_{\mathrm{x}}$ alloys. J. Alloys Compd. 2018, 743, 494-505. [CrossRef]

143. Das, M.; Roy, S.; Khan, N.; Mandal, P. Giant magnetocaloric effect in an exchange-frustrated GdCrTiO 5 antiferromagnet. Phys. Rev. B 2018, 98, 104420. [CrossRef]

144. Cong, D.Y.; Huang, L.; Hardy, V.; Bourgault, D.; Sun, X.M.; Nie, Z.H.; Wang, M.G.; Ren, Y.; Entel, P.; Wang, Y.D. Low-field-actuated giant magnetocaloric effect and excellent mechanical properties in a NiMn-based multiferroic alloy. Acta Mater. 2018, 146, 142-151. [CrossRef]

145. Chen, J.H.; Saleheen, A.U.; Adams, P.W.; Young, D.P.; Ali, N.; Stadler, S. On entropy determination from magnetic and calorimetric experiments in conventional giant magnetocaloric materials. J. Appl. Phys. 2018, 123, 145101. [CrossRef]

146. Chen, F.; Llamazares, J.L.S.; Sanchez-Valdes, C.F.; Mullner, P.; Shi, Y.G.; Tong, Y.X.; Li, L. High temperature martensitic transformation and giant magnetocaloric effect in $\mathrm{Ni}_{40} \mathrm{Co}_{10} \mathrm{Mn}_{41} \mathrm{Sn}_{9}$ melt-spun ribbons. J. Alloys Compd. 2018, 744, 493-501. [CrossRef]

147. Born, N.O.; Caron, L.; Seeler, F.; Felser, C. Tunable giant magnetocaloric effect with very low hysteresis in $\mathrm{Mn}_{3} \mathrm{CuN}_{1-\mathrm{x}} \mathrm{C}_{\mathrm{x}}$. J. Alloys Compd. 2018, 749, 926-930. [CrossRef]

148. Zhao, D.W.; Liu, J.; Chen, X.; Sun, W.; Li, Y.; Zhang, M.X.; Shao, Y.Y.; Zhang, H.; Yan, A.R. Giant caloric effect of low-hysteresis metamagnetic shape memory alloys with exceptional cyclic functionality. Acta Mater. 2017, 133, 217-223. [CrossRef]

149. Yuan, Y.; Wu, Y.; Tong, X.; Zhang, H.; Wang, H.; Liu, X.J.; Ma, L.; Suo, H.L.; Lu, Z.P. Rare-earth high-entropy alloys with giant magnetocaloric effect. Acta Mater. 2017, 125, 481-489. [CrossRef]

150. Thang, N.V.; van Dijk, N.H.; Bruck, E. Tuneable Giant Magnetocaloric Effect in $(\mathrm{Mn}, \mathrm{Fe})_{2}(\mathrm{P}, \mathrm{Si})$ Materials by Co-B and Ni-B Co-Doping. Materials 2017, 10, 14. [CrossRef]

151. Sun, Q.L.; Mo, Z.J.; Shen, J.; Li, Y.J.; Li, L.; Zhang, J.K.; Liu, G.D.; Tang, C.C.; Meng, F.B. Observation of giant magnetocaloric effect under low magnetic fields in $\mathrm{EuTi}_{1-x} \mathrm{Co}_{\mathrm{x}} \mathrm{O}_{3}$. Chin. Phys. B 2017, 26, 117501. [CrossRef]

152. Ruan, M.Y.; Ouyang, Z.W.; Wang, Z.X.; Xia, Z.C.; Rao, G.H. Magnetization, ESR, and giant magnetocaloric effects in nanocrystals of Haldane-chain compound $\mathrm{Gd}_{2} \mathrm{BaNiO}_{5}$. Appl. Phys. Lett. 2017, 111, 122403. [CrossRef]

153. Qu, Y.H.; Cong, D.Y.; Sun, X.M.; Nie, Z.H.; Gui, W.Y.; Li, R.G.; Ren, Y.; Wang, Y.D. Giant and reversible room-temperature magnetocaloric effect in Ti-doped Ni-Co-Mn-Sn magnetic shape memory alloys. Acta Mater. 2017, 134, 236-248. [CrossRef]

154. Perez-Landazabal, J.I.; Recarte, V.; Sanchez-Alarcos, V.; Beato-Lopez, J.J.; Rodriguez-Velamazan, J.A.; Sanchez-Marcos, J.; Gomez-Polo, C.; Cesari, E. Giant direct and inverse magnetocaloric effect linked to the same forward martensitic transformation. Sci. Rep. 2017, 7, 1-8. [CrossRef]

155. Moon, J.Y.; Kim, M.K.; Choi, Y.J.; Lee, N. Giant Anisotropic Magnetocaloric Effect in Double-perovskite $\mathrm{Gd}_{2} \mathrm{CoMnO}_{6}$ Single Crystals. Sci. Rep. 2017, 7, 1-10. [CrossRef]

156. Mo, Z.J.; Sun, Q.L.; Wang, C.H.; Wu, H.Z.; Li, L.; Meng, F.B.; Tang, C.C.; Zhao, Y.; Shen, J. Effects of Sr-doping on the giant magnetocaloric effect of $\mathrm{EuTiO}_{3}$. Ceram. Int. 2017, 43, 2083-2088. [CrossRef]

157. Mo, Z.J.; Hao, Z.H.; Deng, J.Z.; Shen, J.; Li, L.; Wu, J.F.; Hu, F.X.; Sun, J.R.; Shen, B.G. Observation of giant magnetocaloric effect under low magnetic field in $\mathrm{Eu}_{1-x} \mathrm{Ba}_{x} \mathrm{TiO}_{3}$. J. Alloys Compd. 2017, 694, 235-240. [CrossRef]

158. Mahana, S.; Manju, U.; Topwal, D. Giant magnetocaloric effect in $\mathrm{GdAlO}_{3}$ and a comparative study with $\mathrm{GdMnO}_{3}$. J. Phys. D-Appl. Phys. 2017, 50, 035002. [CrossRef]

159. Li, Y.W.; Zhang, H.; Tao, K.; Wang, Y.X.; Wu, M.L.; Long, Y. Giant magnetocaloric effect induced by reemergence of magnetostructural coupling in Si-doped $\mathrm{Mn}_{0.95}$ CoGe compounds. Mater. Des. 2017, 114, 410-415. [CrossRef] 
160. Ho, T.A.; Lim, S.H.; Phan, T.L.; Yu, S.C. Universal curves in assessing the order of magnetic transition of $\mathrm{La}_{0.7-x} \operatorname{PrxCa}_{0.3} \mathrm{MnO}_{3}$ compounds exhibiting giant magnetocaloric effect. J. Alloys Compd. 2017, 692, 687-692. [CrossRef]

161. de Oliveira, N.A. Giant rotating magnetocaloric effect in $\mathrm{RNi}_{5}$ single crystals. J. Phys. Chem. Solids 2017, 103, 13-15. [CrossRef]

162. Das, M.; Roy, S.; Mandal, P. Giant reversible magnetocaloric effect in a multiferroic $\mathrm{GdFeO}_{3}$ single crystal. Phys. Rev. B 2017, 96, 174405. [CrossRef]

163. Cervera, S.; Trassinelli, M.; Marangolo, M.; Carretero, C.; Garcia, V.; Hidki, S.; Jacquet, E.; Lamour, E.; Levy, A.; Mace, S.; et al. Modulating the phase transition temperature of giant magnetocaloric thin films by ion irradiation. Phys. Rev. Mater. 2017, 1, 065402. [CrossRef]

164. Cai, Y.Q.; Jiao, Y.Y.; Cui, Q.; Cai, J.W.; Li, Y.; Wang, B.S.; Fernandez-Diaz, M.T.; McGuire, M.A.; Yan, J.Q.; Alonso, J.A.; et al. Giant reversible magnetocaloric effect in the pyrochlore $\operatorname{Er}_{2} \mathrm{Mn}_{2} \mathrm{O}_{7}$ due to a cooperative two-sublattice ferromagnetic order. Phys. Rev. Mater. 2017, 1, 064408. [CrossRef]

165. Balli, M.; Fournier, P.; Jandl, S.; Mansouri, S.; Mukhin, A.; Ivanov, Y.V.; Balbashov, A.M. Comment on “Giant anisotropy of magnetocaloric effect in $\mathrm{TbMnO}_{3}$ single crystals". Phys. Rev. B 2017, 96, 146401. [CrossRef]

166. Zhang, Y.; Dong, Q.Y.; Wang, L.C.; Zhang, M.; Yan, H.T.; Sun, J.R.; Hu, F.X.; Shen, B.G. Giant low-field reversible magnetocaloric effect in HoCoGe compound. RSC Adv. 2016, 6, 106171-106176. [CrossRef]

167. Zhang, X.X.; Qian, M.F.; Su, R.Z.; Geng, L. Giant room-temperature inverse and conventional magnetocaloric effects in Ni-Mn-In alloys. Mater. Lett. 2016, 163, 274-276. [CrossRef]

168. Sharma, V.K.; Manekar, M.A.; Srivastava, H.; Roy, S.B. Giant magnetocaloric effect near room temperature in the off-stoichiometric Mn-Co-Ge alloy. J. Phys. D-Appl. Phys. 2016, 49, 50LT01. [CrossRef]

169. Sarkar, S.K.; Sarita; Babu, P.D.; Biswas, A.; Siruguri, V.; Krishnan, M. Giant magnetocaloric effect from reverse martensitic transformation in Ni-Mn-Ga-Cu ferromagnetic shape memory alloys. J. Alloys Compd. 2016, 670, 281-288. [CrossRef]

170. Roy, S.; Khan, N.; Mandal, P. Giant low-field magnetocaloric effect in single-crystalline $\mathrm{EuTi}_{0.85} \mathrm{Nb}_{0.15} \mathrm{O}_{3}$. APL Mater. 2016, 4, 026102. [CrossRef]

171. Meng, L.J.; Xu, C.; Yuan, Y.; Qi, Y.; Zhou, S.Q.; Li, L.W. Magnetic properties and giant reversible magnetocaloric effect in $\mathrm{GdCoC}_{2}$. RSC Adv. 2016, 6, 74765-74768. [CrossRef]

172. Madiligama, A.S.B.; Ari-Gur, P.; Shavrov, V.G.; Koledov, V.V.; Calder, S.; Mashirov, A.V.; Kamantsev, A.P.; Dilmieva, E.T.; Gonzalez-Legarreta, L.; Grande, B.H.; et al. Crystalline structure and magnetic behavior of the $\mathrm{Ni}_{41} \mathrm{Mn}_{39} \mathrm{In}_{12} \mathrm{Co}_{8}$ alloy demonstrating giant magnetocaloric effect. Smart Mater. Struct. 2016, 25, 085013. [CrossRef]

173. Guillou, F.; Wilhelm, F.; Tegus, O.; Rogalev, A. Microscopic mechanism of the giant magnetocaloric effect in MnCoGe alloys probed by x-ray magnetic circular dichroism. Appl. Phys. Lett. 2016, 108, 122405. [CrossRef]

174. Das, K.; Das, I. Giant enhancement of magnetocaloric effect at room temperature by the formation of nanoparticle of $\mathrm{La}_{0.48} \mathrm{Ca}_{0.52} \mathrm{MnO}_{3}$ compound. J. Appl. Phys. 2016, 119, 093903. [CrossRef]

175. Chen, J.H.; Bruno, N.M.; Karaman, I.; Huang, Y.J.; Li, J.G.; Ross, J.H. Direct measure of giant magnetocaloric entropy contributions in Ni-Mn-In. Acta Mater. 2016, 105, 176-181. [CrossRef]

176. Cao, Y.M.; Xiang, M.L.; Zhao, W.Y.; Wang, G.H.; Feng, Z.J.; Kang, B.J.; Stroppa, A.; Zhang, J.C.; Ren, W.; Cao, S.X. Magnetic phase transition and giant anisotropic magnetic entropy change in $\mathrm{TbFeO}_{3}$ single crystal. J. Appl. Phys. 2016, 119, 063904. [CrossRef]

177. Brown, T.D.; Karaman, I.; Shamberger, P.J. Impact of cycle-hysteresis interactions on the performance of giant magnetocaloric effect refrigerants. Mater. Res. Express 2016, 3, 074001. [CrossRef]

178. Bao, L.F.; Huang, W.D.; Ren, Y.J. Tuning Martensitic Phase Transition by Non-Magnetic Atom Vacancy in MnCoGe Alloys and Related Giant Magnetocaloric Effect. Chin. Phys. Lett. 2016, 33, 077502. [CrossRef]

179. Balli, M.; Jandl, S.; Fournier, P.; Dimitrov, D.Z. Giant rotating magnetocaloric effect at low magnetic fields in multiferroic $\mathrm{TbMn}_{2} \mathrm{O}_{5}$ single crystals. Appl. Phys. Lett. 2016, 108, 102401. [CrossRef]

180. Amaral, J.S.; Fortunato, N.M.; Amorim, C.; Goncalves, J.N.; Amaral, V.S. Giant Magnetocaloric Effect of Compressible Ising and Heisenberg Lattices. In Proceedings of the 7th International Conference on Magnetic Refrigeration at Room Temperature (Thermag VII), Turin, Italy, 11-14 September 2016; pp. $252-257$. [CrossRef]

181. Zhang, H.; Li, Y.W.; Liu, E.K.; Ke, Y.J.; Jin, J.L.; Long, Y.; Shen, B.G. Giant rotating magnetocaloric effect induced by highly texturing in polycrystalline DyNiSi compound. Sci. Rep. 2015, 5, 11929. [CrossRef] 
182. Zhang, D.; Nie, Z.H.; Wang, Z.L.; Huang, L.A.; Zhang, Q.H.; Wang, Y.D. Giant magnetocaloric effect in MnCoGe with minimal Ga substitution. J. Magn. Magn. Mater. 2015, 387, 107-110. [CrossRef]

183. Yin, L.H.; Yang, J.; Kan, X.C.; Song, W.H.; Dai, J.M.; Sun, Y.P. Giant magnetocaloric effect and temperature induced magnetization jump in $\mathrm{GdCrO}_{3}$ single crystal. J. Appl. Phys. 2015, 117, 133901. [CrossRef]

184. Yibole, H.; Guillou, F.; Caron, L.; Jimenez, E.; de Groot, F.M.F.; Roy, P.; de Groot, R.; van Dijk, N.H.; Bruck, E. Moment evolution across the ferromagnetic phase transition of giant magnetocaloric $(\mathrm{Mn}, \mathrm{Fe})_{2}(\mathrm{P}, \mathrm{Si}, \mathrm{B})$ compounds. Phys. Rev. B 2015, 91, 014429. [CrossRef]

185. Wali, M.; Skini, R.; Khlifi, M.; Dhahri, E.; Hlil, E.K. A giant magnetocaloric effect with a tunable temperature transition close to room temperature in Na-deficient $\mathrm{La}_{0.8} \mathrm{Na}_{0.2-\mathrm{x}} \square_{\mathrm{x}} \mathrm{MnO}_{3}$ manganites. Dalton Trans. 2015, 44, 12796-12803. [CrossRef]

186. Wagh, A.A.; Suresh, K.G.; Kumar, P.S.A.; Elizabeth, S. Low temperature giant magnetocaloric effect in multiferroic $\mathrm{GdMnO}_{3}$ single crystals. J. Phys. D-Appl. Phys. 2015, 48, 135001. [CrossRef]

187. Toyoizumi, S.; Kitazawa, H.; Kawamura, Y.; Mamiya, H.; Terada, N.; Tamura, R.; Donni, A.; Morita, K.; Tamaki, A. Sample dependence of giant magnetocaloric effect in a cluster-glass system $\mathrm{Ho}_{5} \mathrm{Pd}_{2}$. J. Appl. Phys. 2015, 117, 17D101. [CrossRef]

188. Tkac, V.; Orendacova, A.; Cizmar, E.; Orendac, M.; Feher, A.; Anders, A.G. Giant reversible rotating cryomagnetocaloric effect in $\mathrm{KEr}\left(\mathrm{MoO}_{4}\right)_{2}$ induced by a crystal-field anisotropy. Phys. Rev. B 2015, 92, 024406. [CrossRef]

189. Teichert, N.; Kucza, D.; Yildirim, O.; Yuzuak, E.; Dincer, I.; Behler, A.; Weise, B.; Helmich, L.; Boehnke, A.; Klimova, S.; et al. Structure and giant inverse magnetocaloric effect of epitaxial Ni-Co-Mn-Al films. Phys. Rev. B 2015, 91, 184405. [CrossRef]

190. Teichert, N.; Kucza, D.; Yildirim, O.; Hetaba, W.; Behler, A.; Yuzuak, E.; Dincer, I.; Helmich, L.; Boehnke, A.; Stoger-Pollach, M.; et al. Structure and Giant Inverse Magnetocaloric Effect of Epitaxial Ni-Co-Mn-Al Films. In Proceedings of the 2015 IEEE International Magnetics Conference (InterMag 2015), Beijing, China, 11-15 May 2015.

191. Strecka, J.; Karlova, K.; Madaras, T. Giant magnetocaloric effect, magnetization plateaux and jumps of the regular Ising polyhedra. Phys. B-Condens. Matter 2015, 466, 76-85. [CrossRef]

192. Rodionov, I.D.; Koshkid'ko, Y.S.; Cwik, J.; Quetz, A.; Pandey, S.; Aryala, A.; Dubenko, I.S.; Stadler, S.; Ali, N.; Titov, I.S.; et al. Peculiarities of giant magnetocaloric effect in $\mathrm{Ni}_{50} \mathrm{Mn}_{35} \mathrm{In}_{15}$ alloys in the vicinity of martensitic transition. In Proceedings of the 20th International Conference on Magnetism (ICM 2015); Barcelona, Spain, 5-10 July 2015. Phys. Procedia 2015, 75, 1353-1359. [CrossRef]

193. Murthy, J.K.; Chandrasekhar, K.D.; Mahana, S.; Topwal, D.; Venimadhav, A. Giant magnetocaloric effect in $\mathrm{Gd}_{2} \mathrm{NiMnO}_{6}$ and $\mathrm{Gd}_{2} \mathrm{CoMnO}_{6}$ ferromagnetic insulators. J. Phys. D-Appl. Phys. 2015, 48, 355001. [CrossRef]

194. Mo, Z.J.; Shen, J.; Yan, L.Q.; Gao, X.Q.; Tang, C.C.; Wu, J.F.; Sun, J.R.; Shen, B.G. A giant reversible magnetocaloric effect in $\mathrm{Ho}_{2} \mathrm{PdSi}_{3}$ compound. J. Alloys Compd. 2015, 618, 512-515. [CrossRef]

195. Mo, Z.J.; Shen, J.; Li, L.; Liu, Y.; Tang, C.C.; Hu, F.X.; Sun, J.R.; Shen, B.G. Observation of giant magnetocaloric effect in $\mathrm{EuTiO}_{3}$. Mater. Lett. 2015, 158, 282-284. [CrossRef]

196. Mo, Z.J.; Hao, Z.H.; Shen, J.; Li, L.; Wu, J.F.; Hu, F.X.; Sun, J.R.; Shen, B.G. Observation of giant magnetocaloric effect in $\mathrm{EuTi}_{1-\mathrm{x}} \mathrm{Cr}_{\mathrm{x}} \mathrm{O}_{3}$. J. Alloys Compd. 2015, 649, 674-678. [CrossRef]

197. Min, J.X.; Zhong, X.C.; Franco, V.; Tian, H.C.; Liu, Z.W.; Zheng, Z.G.; Zeng, D.C. Structure, magnetic properties and giant magnetocaloric effect of $\mathrm{Tb}_{4} \mathrm{Gd}_{1} \mathrm{Si}_{2.035} \mathrm{Ge}_{1.935} \mathrm{Mn}_{0.03}$ alloy. Intermetallics 2015, 57, 68-72. [CrossRef]

198. Li, L.W.; Yuan, Y.; Zhang, Y.K.; Namiki, T.; Nishimura, K.; Pottgen, R.; Zhou, S.Q. Giant low field magnetocaloric effect and field-induced metamagnetic transition in TmZn. Appl. Phys. Lett. 2015, 107, 132401. [CrossRef]

199. Ke, Y.J.; Zhang, X.Q.; Ge, H.; Ma, Y.; Cheng, Z.H. Low field induced giant anisotropic magnetocaloric effect in $\mathrm{DyFeO}_{3}$ single crystal. Chin. Phys. B 2015, 24, 037501. [CrossRef]

200. Hou, X.L.; Lampen-Kelley, P.; Xue, Y.; Liu, C.Y.; Xu, H.; Han, N.; Ma, C.W.; Srikanth, H.; Phan, M.H. Formation mechanisms of $\mathrm{NaZn}_{13}$-type phase in giant magnetocaloric La-Fe-Si compounds during rapid solidification and annealing. J. Alloys Compd. 2015, 646, 503-511. [CrossRef]

201. Guillou, F.; Ollefs, K.; Wilhelm, F.; Rogalev, A.; Yaresko, A.N.; Yibole, H.; van Dijk, N.H.; Bruck, E. Electronic and magnetic properties of phosphorus across the first-order ferromagnetic transition of $(\mathrm{Mn}, \mathrm{Fe})_{2}(\mathrm{P}, \mathrm{Si}, \mathrm{B})$ giant magnetocaloric materials. Phys. Rev. B 2015, 92, 224427. [CrossRef] 
202. Dong, Q.Y.; Ma, Y.; Ke, Y.J.; Zhang, X.Q.; Wang, L.C.; Shen, B.G.; Sun, J.R.; Cheng, Z.H. Ericsson-like giant magnetocaloric effect in $\mathrm{GdCrO}_{4}-\mathrm{ErCrO}_{4}$ composite oxides near liquid hydrogen temperature. Mater. Lett. 2015, 161, 669-673. [CrossRef]

203. Cervera, S.; Trassinelli, M.; Marangolo, M.; Carlsson, L.B.; Eddrief, M.; Etgens, V.H.; Gafton, V.; Hidki, S.; Lamour, E.; Levy, A.; et al. Hints on the origin of the thermal hysteresis suppression in giant magnetocaloric thin films irradiated with highly charged ions. In Proceedings of the XXIX International Conference on Photonic, Electronic, and Atomic Collisions (ICPEAC 2015), Toledo, Spain, 22-28 July 2015. J. Phys. Conf. Ser. 2015, 635, 012028. [CrossRef]

204. Bruno, N.M.; Karaman, I.; Ross, J.H.; Huang, Y.J.J.; Li, J.G.G. The Tunable Microstructure and Its Influence on the Giant Magnetocaloric Effect in Magnetic Shape Memory Alloys. In Proceedings of the TMS Middle East-Mediterranean Materials Congress on Energy and Infrastructure Systems (MEMA 2015), Doha, Qatar, 11-14 January 2015; pp. 139-147. [CrossRef]

205. Wada, H.; Nakamura, K.; Katagiri, K.; Ohnishi, T.; Yamashita, K.; Matsushita, A. Tuning the Curie temperature and thermal hysteresis of giant magnetocaloric $(\mathrm{MnFe})_{2} \mathrm{PX}(\mathrm{X}=\mathrm{Ge}$ and $\mathrm{Si})$ compounds by the Ru substitution. Jpn. J. Appl. Phys. 2014, 53, 063001. [CrossRef]

206. Rubi, K.; Kumar, P.; Repaka, D.V.M.; Chen, R.F.; Wang, J.S.; Mahendiran, R. Giant magnetocaloric effect in magnetoelectric $\mathrm{Eu}_{1-\mathrm{x}} \mathrm{Ba}_{\mathrm{x}} \mathrm{TiO}_{3}$. Appl. Phys. Lett. 2014, 104, 032407. [CrossRef]

207. Mohamed, Z.; Tka, E.; Dhahri, J.; Hlil, E.K. Giant magnetic entropy change in manganese perovskite $\mathrm{La}_{0.67} \mathrm{Sr}_{0.16} \mathrm{Ca}_{0.17} \mathrm{MnO}_{3}$ near room temperature. J. Alloys Compd. 2014, 615, 290-297.

208. Midya, A.; Mandal, P. Giant magnetocaloric effect in ferromagnetic superconductor $\mathrm{RuSr}_{2} \mathrm{GdCu}_{2} \mathrm{O}_{8}$. J. Appl. Phys. 2014, 116, 032407. [CrossRef]

209. Midya, A.; Khan, N.; Bhoi, D.; Mandal, P. Giant magnetocaloric effect in antiferromagnetic DyVO $\mathrm{V}_{4}$ compound. Phys. B-Condens. Matter 2014, 448, 43-45. [CrossRef]

210. Marangolo, M.; Karboul-Trojet, W.; Prieur, J.Y.; Etgens, V.H.; Eddrief, M.; Becerra, L.; Duquesne, J.Y. Surface acoustic wave triggering of giant magnetocaloric effect in MnAs/GaAs devices. Appl. Phys. Lett. 2014, 105, 162403. [CrossRef]

211. Ma, S.C.; Hou, D.; Gong, Y.Y.; Wang, L.Y.; Huang, Y.L.; Zhong, Z.C.; Wang, D.H.; Du, Y.W. Giant magnetocaloric and magnetoresistance effects in ferrimagnetic $\mathrm{Mn}_{1.9} \mathrm{Co}_{0.1} \mathrm{Sb}$ alloy. Appl. Phys. Lett. 2014, 104, 022410. [CrossRef]

212. Liu, X.G.; Feng, C.; Xiao, F.; Or, S.W.; Sun, Y.P.; Jin, C.G.; Xia, A.L. Giant Reversible Magnetocaloric Effect in Flower-like beta- $\mathrm{Co}(\mathrm{OH})_{2}$ Hierarchical Superstructures Self-assembled by Nanosheets. Mater. Res.-Ibero-Am. J. Mater. 2014, 17, 186-189.

213. Li, Z.B.; Zhang, Y.D.; Sanchez-Valdes, C.F.; Llamazares, J.L.S.; Esling, C.; Zhao, X.; Zuo, L. Giant magnetocaloric effect in melt-spun Ni-Mn-Ga ribbons with magneto-multistructural transformation. Appl. Phys. Lett. 2014, 104, 044101. [CrossRef]

214. Huang, L.; Cong, D.Y.; Suo, H.L.; Wang, Y.D. Giant magnetic refrigeration capacity near room temperature in $\mathrm{Ni}_{40} \mathrm{Co}_{10} \mathrm{Mn}_{40} \mathrm{Sn}_{10}$ multifunctional alloy. Appl. Phys. Lett. 2014, 104, 132407. [CrossRef]

215. Guillou, F.; Yibole, H.; van Dijk, N.H.; Zhang, L.; Hardy, V.; Bruck, E. About the mechanical stability of $\mathrm{MnFe}(\mathrm{P}, \mathrm{Si}, \mathrm{B})$ giant-magnetocaloric materials. J. Alloys Compd. 2014, 617, 569-574. [CrossRef]

216. Guillou, F.; Porcari, G.; Yibole, H.; van Dijk, N.; Bruck, E. Taming the First-Order Transition in Giant Magnetocaloric Materials. Adv. Mater. 2014, 26, 2671-2675. [CrossRef]

217. Das, P.K.; Bhattacharyya, A.; Kulkarni, R.; Dhar, S.K.; Thamizhavel, A. Anisotropic magnetic properties and giant magnetocaloric effect of single-crystal PrSi. Phys. Rev. B 2014, 89, 134418. [CrossRef]

218. Comtesse, D.; Gruner, M.E.; Ogura, M.; Sokolovskiy, V.V.; Buchelnikov, V.D.; Grunebohm, A.; Arroyave, R.; Singh, N.; Gottschall, T.; Gutfleisch, O.; et al. First-principles calculation of the instability leading to giant inverse magnetocaloric effects. Phys. Rev. B 2014, 89, 184403. [CrossRef]

219. Chen, F.H.; Gong, C.W.; Guo, Y.P.; Zhang, M.G.; Chai, Y.S. Martensitic transformation and giant magnetic entropy change in $\mathrm{Ni}_{42.8} \mathrm{Mn}_{40.3} \mathrm{Co}_{5.7} \mathrm{Sn}_{11.2}$ alloy. Chin. Phys. B 2014, 23, 067501. [CrossRef]

220. Boutahar, A.; Lassri, H.; Hlil, E.K. Low Temperature Giant Magnetocaloric Effect and Critical Behavior in Amorphous $\mathrm{Co}_{100-\mathrm{x}} \mathrm{Er}_{\mathrm{x}}(\mathrm{x}=55,65)$ Alloys. J. Supercond. Nov. Magn. 2014, 27, 2865-2869. [CrossRef]

221. Balli, M.; Jandl, S.; Fournier, P.; Gospodinov, M.M. Anisotropy-enhanced giant reversible rotating magnetocaloric effect in $\mathrm{HoMn}_{2} \mathrm{O}_{5}$ single crystals. Appl. Phys. Lett. 2014, 104, 232402. [CrossRef] 
222. Zhou, T.J.; Cher, M.K.; Shen, L.; Hu, J.F.; Yuan, Z.M. On the origin of giant magnetocaloric effect and thermal hysteresis in multifunctional alpha-FeRh thin films. Phys. Lett. A 2013, 377, 3052-3059. [CrossRef]

223. Zheng, X.Q.; Shao, X.P.; Chen, J.; Xu, Z.Y.; Hu, F.X.; Sun, J.R.; Shen, B.G. Giant magnetocaloric effect in $\mathrm{Ho}_{12} \mathrm{Co}_{7}$ compound. Appl. Phys. Lett. 2013, 102, 022421. [CrossRef]

224. Wang, L.C.; Dong, Q.Y.; Mo, Z.J.; Xu, Z.Y.; Hu, F.X.; Sun, J.R.; Shen, B.G. Low-temperature reversible giant magnetocaloric effect in the HoCuAl compound. J. Appl. Phys. 2013, 114, 163915. [CrossRef]

225. Vopson, M.M. Theory of giant-caloric effects in multiferroic materials. J. Phys. D-Appl. Phys. 2013, 46, 345304. [CrossRef]

226. Nguyen, H.D.; Do, T.H.; Nguyen, H.Y.; Pham, T.T.; Nguyen, H.D.; Nguyen, T.N.N.; Tran, D.T.; Phan, T.L.; $\mathrm{Yu}$, S.C. Influence of fabrication conditions on giant magnetocaloric effect of Ni-Mn-Sn ribbons. Adv. Nat. Sci.-Nanosci. Nanotechnol. 2013, 4, 025011. [CrossRef]

227. Moya, X.; Hueso, L.E.; Maccherozzi, F.; Tovstolytkin, A.I.; Podyalovskii, D.I.; Ducati, C.; Phillips, L.C.; Ghidini, M.; Hovorka, O.; Berger, A.; et al. Giant and reversible extrinsic magnetocaloric effects in $\mathrm{La}_{0.7} \mathrm{Ca}_{0.3} \mathrm{MnO}_{3}$ films due to strain. Nat. Mater. 2013, 12, 52-58. [CrossRef]

228. Mo, Z.J.; Shen, J.; Yan, L.Q.; Wu, J.F.; Wang, L.C.; Lin, J.; Tang, C.C.; Shen, B.G. Low-field induced giant magnetocaloric effect in TmCuAl compound. Appl. Phys. Lett. 2013, 102, 192407. [CrossRef]

229. Mo, Z.J.; Shen, J.; Yan, L.Q.; Tang, C.C.; Lin, J.; Wu, J.F.; Sun, J.R.; Wang, L.C.; Zheng, X.Q.; Shen, B.G. Low field induced giant magnetocaloric effect in TmGa compound. Appl. Phys. Lett. 2013, 103, 052409. [CrossRef]

230. Midya, A.; Khan, N.; Bhoi, D.; Mandal, P. 3d-4f spin interaction induced giant magnetocaloric effect in zircon-type $\mathrm{DyCrO}_{4}$ and $\mathrm{HoCrO}_{4}$ compounds. Appl. Phys. Lett. 2013, 103, 092402. [CrossRef]

231. Liu, E.K.; Zhang, H.G.; Xu, G.Z.; Zhang, X.M.; Ma, R.S.; Wang, W.H.; Chen, J.L.; Zhang, H.W.; Wu, G.H.; Feng, L.; et al. Giant magnetocaloric effect in isostructural MnNiGe-CoNiGe system by establishing a Curie-temperature window. Appl. Phys. Lett. 2013, 102, 122405. [CrossRef]

232. Li, D.X.; Yamamura, T.; Nimori, S.; Homma, Y.; Honda, F.; Aoki, D. Giant and isotropic low temperature magnetocaloric effect in magnetic semiconductor EuSe. Appl. Phys. Lett. 2013, 102, 152409. [CrossRef]

233. Huo, J.T.; Zhao, D.Q.; Bai, H.Y.; Axinte, E.; Wang, W.H. Giant magnetocaloric effect in Tm-based bulk metallic glasses. J. Non-Cryst. Solids 2013, 359, 1-4. [CrossRef]

234. Gupta, S.B.; Suresh, K.G. Giant low field magnetocaloric effect in soft ferromagnetic ErRuSi. Appl. Phys. Lett. 2013, 102, 022408. [CrossRef]

235. Gupta, S.; Suresh, K.G. Observation of giant magnetocaloric effect in HoCoSi. Mater. Lett. 2013, 113, $195-197$. [CrossRef]

236. Caron, L.; Miao, X.F.; Klaasse, J.C.P.; Gama, S.; Bruck, E. Tuning the giant inverse magnetocaloric effect in $\mathrm{Mn}_{2-\mathrm{x}} \mathrm{Cr}_{\mathrm{x}} \mathrm{Sb}$ compounds. Appl. Phys. Lett. 2013, 103, 112404. [CrossRef]

237. Zhang, H.; Xu, Z.Y.; Zheng, X.Q.; Shen, J.; Hua, F.X.; Sun, J.R.; Shen, B.G. Giant magnetic refrigerant capacity in $\mathrm{Ho}_{3} \mathrm{Al}_{2}$ compound. Solid State Commun. 2012, 152, 1127-1130. [CrossRef]

238. Pankratov, N.Y.; Mitsiuk, V.I.; Krokhotin, A.I.; Smarzhevskaya, A.I.; Govor, G.A.; Nikitin, S.A.; Ryzhkovskii, V.M. Giant magnetocaloric effect in the region of magnetic phase transition in $\mathrm{Mn}(\mathrm{As}, \mathrm{Sb})$ compounds. Magn. Magn. Mater. V 2012, 190, 343-346. [CrossRef]

239. Ou, Z.Q.; Caron, L.; Dung, N.H.; Zhang, L.; Bruck, E. Interstitial boron in MnFe(P,As) giant-magnetocaloric alloy. Results Phys. 2012, 2, 110-113. [CrossRef]

240. Midya, A.; Khan, N.; Bhoi, D.; Mandal, P. Giant magnetocaloric effect in magnetically frustrated $\mathrm{EuHo}_{2} \mathrm{O}_{4}$ and $\mathrm{EuDy}_{2} \mathrm{O}_{4}$ compounds. Appl. Phys. Lett. 2012, 101, 132415. [CrossRef]

241. Liu, J.; Gottschall, T.; Skokov, K.P.; Moore, J.D.; Gutfleisch, O. Giant magnetocaloric effect driven by structural transitions. Nat. Mater. 2012, 11, 620-626. [CrossRef] [PubMed]

242. Li, L.W.; Nishimura, K.; Hutchison, W.D.; Qian, Z.H.; Huo, D.X.; NamiKi, T. Giant reversible magneto-caloric effect in $\mathrm{ErMn}_{2} \mathrm{Si}_{2}$ compound with a second order magnetic phase transition. Appl. Phys. Lett. 2012, 100, 152403. [CrossRef]

243. Li, L.W.; Kadonaga, M.; Huo, D.X.; Qian, Z.H.; Namiki, T.; Nishimura, K. Low field giant magnetocaloric effect in $\mathrm{RNiBC}(\mathrm{R}=\mathrm{Er}$ and $\mathrm{Gd})$ and enhanced refrigerant capacity in its composite materials. Appl. Phys. Lett. 2012, 101, 122401. [CrossRef]

244. Li, L.W.; Hutchison, W.D.; Huo, D.X.; Namiki, T.; Qian, Z.H.; Nishimura, K. Low-field giant reversible magnetocaloric effect in intermetallic compound $\mathrm{ErCr}_{2} \mathrm{Si}_{2}$. Scr. Mater. 2012, 67, 237-240. [CrossRef] 
245. Duquesne, J.Y.; Prieur, J.Y.; Canalejo, J.A.; Etgens, V.H.; Eddrief, M.; Ferreira, A.L.; Marangolo, M. Ultrasonic triggering of giant magnetocaloric effect in MnAs thin films. Phys. Rev. B 2012, 86, 035207. [CrossRef]

246. Dung, D.D.; Tuan, D.A.; Thiet, D.V.; Shin, Y.; Cho, S. Giant magnetocaloric effect of $\mathrm{Mn}_{0.92} \mathrm{Ba}_{0.08} \mathrm{As}$ thin film grown on $\mathrm{Al}_{2} \mathrm{O}_{3}$ substrate. J. Appl. Phys. 2012, 111, 07C310.

247. Midya, A.; Das, S.N.; Mandal, P.; Pandya, S.; Ganesan, V. Anisotropic magnetic properties and giant magnetocaloric effect in antiferromagnetic $\mathrm{RMnO}_{3}$ crystals $(\mathrm{R}=\mathrm{Dy}, \mathrm{Tb}, \mathrm{Ho}$, and $\mathrm{Yb})$. Phys. Rev. B 2011, 84, 235127. [CrossRef]

248. Medeiros, F.C.; Mello, V.D.; Dantas, A.L.; Sales, F.H.S.; Carrico, A.S. Giant magnetocaloric effect of thin Ho films. J. Appl. Phys. 2011, 109, 07A914.

249. Manosa, L.; Gonzalez-Alonso, D.; Planes, A.; Barrio, M.; Tamarit, J.L.; Titov, I.S.; Acet, M.; Bhattacharyya, A.; Majumdar, S. Inverse barocaloric effect in the giant magnetocaloric La-Fe-Si-Co compound. Nat. Commun. 2011, 2, 1-5. [CrossRef] [PubMed]

250. Li, L.W.; Nishimura, K.; Kadonaga, M.; Qian, Z.H.; Huo, D.X. Giant magnetocaloric effect in antiferromagnetic borocarbide superconductor $\mathrm{RNi}_{2} \mathrm{~B}_{2} \mathrm{C}(\mathrm{R}=\mathrm{Dy}, \mathrm{Ho}$, and Er) compounds. J. Appl. Phys. 2011, 110, 043912. [CrossRef]

251. Kim, M.S.; Sung, N.H.; Son, Y.; Ko, M.S.; Cho, B.K. Giant reversible anisotropic magnetocaloric effect in an antiferromagnetic $\mathrm{EuFe}_{2} \mathrm{As}_{2}$ single crystal. Appl. Phys. Lett. 2011, 98, 172509. [CrossRef]

252. Jin, J.L.; Zhang, X.Q.; Li, G.K.; Cheng, Z.H.; Zheng, L.; Lu, Y. Giant anisotropy of magnetocaloric effect in $\mathrm{TbMnO}_{3}$ single crystals. Phys. Rev. B 2011, 83, 184431. [CrossRef]

253. Fabbrici, S.; Kamarad, J.; Arnold, Z.; Casoli, F.; Paoluzi, A.; Bolzoni, F.; Cabassi, R.; Solzi, M.; Porcari, G.; Pernechele, C.; et al. From direct to inverse giant magnetocaloric effect in Co-doped NiMnGa multifunctional alloys. Acta Mater. 2011, 59, 412-419. [CrossRef]

254. Zhang, Y.; Zhang, P.; Kim, K.; Yu, S.C.; Dan, N.H.; Hou, X.L. Magnetic Properties and Giant Magnetocaloric Effects on the $\mathrm{NiMn}_{0.9} \mathrm{Sb}_{0.1}$ Compound. J. Korean Phys. Soc. 2010, 57, 1983-1986.

255. Yuzuak, E.; Emre, B.; Elerman, Y.; Yucel, A. Giant magnetocaloric effect in $\mathrm{Tb}_{5} \mathrm{Ge}_{2-x} \mathrm{Si}_{2-x} \mathrm{Mn}_{2 \mathrm{x}}$ compounds. Chin. Phys. B 2010, 19, 057501.

256. Xu, P.F.; Nie, S.H.; Meng, K.K.; Wang, S.L.; Chen, L.; Zhao, J.H. Co doping enhanced giant magnetocaloric effect in $\mathrm{Mn}_{1-\mathrm{x}} \mathrm{Co}_{\mathrm{x}}$ As films epitaxied on GaAs (001). Appl. Phys. Lett. 2010, 97, 042502. [CrossRef]

257. Trung, N.T.; Zhang, L.; Caron, L.; Buschow, K.H.J.; Bruck, E. Giant magnetocaloric effects by tailoring the phase transitions. Appl. Phys. Lett. 2010, 96, 172504. [CrossRef]

258. Szymczak, R.; Kolano, R.; Kolano-Burian, A.; Dyakonov, V.P.; Szymczak, H. Giant Magnetocaloric Effect in Manganites. Acta Phys. Pol. A 2010, 117, 203-206. [CrossRef]

259. Shamba, P.; Zeng, R.; Wang, J.Q.; Dou, S.X. A sign of field-induced first order magnetic state transition and giant reversible magnetocaloric effect in cobalt hydroxide nanosheets. J. Appl. Phys. 2010, 107, 09A919. [CrossRef]

260. Nikitin, S.A.; Skokov, K.P.; Koshkid'ko, Y.S.; Pastushenkov, Y.G.; Ivanova, T.I. Giant Rotating Magneto-caloric Effect in the Region of Spin-Reorientation Transition in the $\mathrm{NdCo}_{5}$ Single Crystal. Phys. Rev. Lett. 2010, 105, 137205. [CrossRef] [PubMed]

261. Manosa, L.; Gonzalez-Alonso, D.; Planes, A.; Bonnot, E.; Barrio, M.; Tamarit, J.L.; Aksoy, S.; Acet, M. Giant solid-state barocaloric effect in the Ni-Mn-In magnetic shape-memory alloy. Nat. Mater. 2010, 9, 478-481. [CrossRef] [PubMed]

262. Mahato, R.N.; Sethupathi, K.; Sankaranarayanan, V.; Nirmala, R. Co-existence of giant magnetoresistance and large magnetocaloric effect near room temperature in nanocrystalline $\mathrm{La}_{0.7} \mathrm{Te}_{0.3} \mathrm{MnO}_{3}$. J. Magn. Magn. Mater. 2010, 322, 2537-2540. [CrossRef]

263. Li, D.X.; Nimori, S.; Shikama, T. Giant and anisotropic magnetocaloric effect in antiferromagnetic single crystalline DySb. Solid State Commun. 2010, 150, 1865-1868. [CrossRef]

264. Debnath, J.C.; Zeng, R.; Kim, J.H.; Dou, S.X. Giant magnetic entropy change in colossal magnetoresistance in $\mathrm{La}_{0.7} \mathrm{Ca}_{0.3} \mathrm{MnO}_{3}$ material in low field. J. Appl. Phys. 2010, 107, 09A916. [CrossRef]

265. de Medeiros, L.G.; de Oliveira, N.A.; Troper, A. Giant magnetocaloric and barocaloric effects in $\mathrm{Mn}\left(\mathrm{As}_{1-\mathrm{x}} \mathrm{Sb}_{\mathrm{x}}\right)$. J. Alloys Compd. 2010, 501, 177-182. [CrossRef]

266. Chen, J.; Shen, B.G.; Dong, Q.Y.; Sun, J.R. Giant magnetic entropy change in antiferromagnetic DyCuSi compound. Solid State Commun. 2010, 150, 1429-1431. [CrossRef] 
267. Chen, J.; Shen, B.G.; Dong, Q.Y.; Sun, J.R. Giant magnetocaloric effect in HoGa compound over a large temperature span. Solid State Commun. 2010, 150, 157-159. [CrossRef]

268. Chen, J.; Shen, B.G.; Dong, Q.Y.; Hu, F.X.; Sun, J.R. Giant reversible magnetocaloric effect in metamagnetic HoCuSi compound. Appl. Phys. Lett. 2010, 96, 152501. [CrossRef]

269. Belozorov, D.P.; Lubyaniy, L.Z.; Ravlik, A.G.; Rusakova, A.V.; Samofalov, V.N. Prospects of Development of Magnetizing Systems with Strong Stray Field for Refrigerators Based on Giant Magnetocaloric Effect. Metallofiz. I Noveishie Tekhnol. 2010, 32, 1591-1599.

270. Talik, E.; Klimczak, M. Giant magnetocaloric effect in $\mathrm{Tb}_{3}$ Rh. J. Alloys Compd. 2009, 486, L30-L33. [CrossRef]

271. Li, L.W.; Nishimura, K.; Yamane, H. Giant reversible magnetocaloric effect in antiferromagnetic $\mathrm{GdCo}_{2} \mathrm{~B}_{2}$ compound. Appl. Phys. Lett. 2009, 94, 102509. [CrossRef]

272. Li, L.W.; Nishimura, K. Giant reversible magnetocaloric effect in antiferromagnetic superconductor $\mathrm{Dy}_{0.9} \mathrm{Tm}_{0.1} \mathrm{Ni}_{2} \mathrm{~B}_{2} \mathrm{C}$ compound. Appl. Phys. Lett. 2009, 95, 132505. [CrossRef]

273. Zou, J.D.; Wada, H.; Shen, B.G.; Sun, J.R.; Li, W. Giant magnetocaloric effect and soft-mode magneto-structural phase transition in MnAs. EPL 2008, 81, 47002. [CrossRef]

274. Wang, Y.T.; Bai, H.Y.; Pan, M.X.; Zhao, D.Q.; Wang, W.H. Giant enhancement of magnetocaloric effect in metallic glass matrix composite. Sci. China Ser. G-Phys. Mech. Astron. 2008, 51, 337-348. [CrossRef]

275. von Ranke, P.J.; de Oliveira, N.A.; Plaza, E.J.R.; de Sousa, V.S.R.; Alho, B.P.; Carvalho, A.M.G.; Gama, S.; Reis, M.S. The giant anisotropic magnetocaloric effect in DyAl 2 . J. Appl. Phys. 2008, 104, 093906. [CrossRef]

276. Sun, N.K.; Cui, W.B.; Li, D.; Geng, D.Y.; Yang, F.; Zhang, Z.D. Giant room-temperature magnetocaloric effect in $\mathrm{Mn}_{1-\mathrm{x}} \mathrm{Cr}_{\mathrm{x}}$ As. Appl. Phys. Lett. 2008, 92, 072504. [CrossRef]

277. Phan, M.H.; Woods, G.T.; Chaturvedi, A.; Stefanoski, S.; Nolas, G.S.; Srikanth, H. Long-range ferro-magnetism and giant magnetocaloric effect in type VIII Eu $8 \mathrm{Ga}_{16} \mathrm{Ge}_{30}$ clathrates. Appl. Phys. Lett. 2008, 93, 252505. [CrossRef]

278. Manekar, M.; Roy, S.B. Reproducible room temperature giant magnetocaloric effect in Fe-Rh. J. Phys. D-Appl. Phys. 2008, 41, 192004. [CrossRef]

279. Manekar, M.; Roy, S.B. Thermomagnetic history effects across the first order magneto-structural transition in the giant magnetocaloric Fe-Rh alloy. Eur. Phys. J. B 2008, 64, 19-25. [CrossRef]

280. Liu, X.H.; Liu, W.; Hu, W.J.; Guo, S.; Lv, X.K.; Cui, W.B.; Zhao, X.G.; Zhang, Z.D. Giant reversible magnetocaloric effect in cobalt hydroxide nanoparticles. Appl. Phys. Lett. 2008, 93, 202502. [CrossRef]

281. Huu, C.X.; Chau, N.; The, N.D.; Hoa, N.Q. Giant magnetocaloric effect at room temperature and low-field change in $\mathrm{Fe}_{78-\mathrm{x}} \mathrm{Cr}_{\mathrm{x}} \mathrm{Si}_{4} \mathrm{Nb}_{5} \mathrm{~B}_{12} \mathrm{Cu}_{1}$ amorphous alloys. J. Korean Phys. Soc. 2008, 53, 763-765. [CrossRef]

282. Balli, M.; Fruchart, D.; Gignoux, D.; Dupuis, C.; Kedous-Lebouc, A.; Zach, R. Giant magnetocaloric effect in $\mathrm{Mn}_{1-\mathrm{x}}\left(\mathrm{Ti}_{0.5} \mathrm{~V}_{0.5}\right)_{\mathrm{x}} \mathrm{As}$ : Experiments and calculations. J. Appl. Phys. 2008, 103, 103908. [CrossRef]

283. Zhang, X.X.; Zhang, B.; Yu, S.; Liu, Z.; Xu, W.; Liu, G.; Chen, J.; Cao, Z.; Wu, G. Combined giant inverse and normal magnetocaloric effect for room-temperature magnetic cooling. Phys. Rev. B 2007, 76, 132403. [CrossRef]

284. Xie, S.H.; Li, J.Q.; Zhuang, Y.H. Influence of boron on the giant magnetocaloric effect of $\mathrm{La}\left(\mathrm{Fe}_{0.9} \mathrm{Si}_{0.1}\right)_{13}$. J. Magn. Magn. Mater. 2007, 311, 589-593. [CrossRef]

285. Ulyanov, A.N.; Kim, J.S.; Shin, G.M.; Kang, Y.M.; Yoo, S.I. Giant magnetic entropy change in $\mathrm{La}_{0.7} \mathrm{Ca}_{0.3} \mathrm{MnO}_{3}$ in low magnetic field. J. Phys. D-Appl. Phys. 2007, 40, 123-126. [CrossRef]

286. Samanta, T.; Das, I.; Banerjee, S. Giant magnetocaloric effect in antiferromagnetic $\mathrm{ErRu}_{2} \mathrm{Si}_{2}$ compound. Appl. Phys. Lett. 2007, 91, 152506. [CrossRef]

287. Du, J.; Cui, W.B.; Zhang, Q.; Ma, S.; Xiong, D.K.; Zhang, Z.D. Giant magnetocaloric effect in epsilon-( $\left.\mathrm{Mn}_{0.83} \mathrm{Fe}_{0.17}\right)_{3.25} \mathrm{Ge}$ antiferromagnet. Appl. Phys. Lett. 2007, 90, 042510. [CrossRef]

288. Xu, C.; Li, G.D.; Wang, L.G. Itinerant-electron metamagnetic transition and giant magnetocaloric effect in $\mathrm{La}_{0.8} \mathrm{Ce}_{0.2} \mathrm{Fe}_{11.4} \mathrm{Si}_{1.6}$ compound. J. Appl. Phys. 2006, 99, 123913. [CrossRef]

289. Tocado, L.; Palacios, E.; Burriel, R. Adiabatic measurement of the giant magnetocaloric effect in MnAs. J. Therm. Anal. Calorim. 2006, 84, 213-217. [CrossRef]

290. Sun, Y.; Arnold, Z.; Kamarad, J.; Wang, G.J.; Shen, B.G.; Cheng, Z.H. Pressure enhancement of the giant magnetocaloric effect in $\mathrm{LaFe}_{11.6} \mathrm{Si}_{1.4}$. Appl. Phys. Lett. 2006, 89, 172513. [CrossRef]

291. Srinath, S.; Gass, J.; Rebar, D.J.; Woods, G.T.; Srikanth, H.; Nolas, G.S. Giant magnetocaloric effect in clathrates. J. Appl. Phys. 2006, 99, 08K902. [CrossRef] 
292. Li, J.Q.; Liu, F.S.; Ao, W.Q.; Zhuang, Y.H.; Zhou, K.W. Influence of carbon on the giant magnetocaloric effect of $\mathrm{LaFe}_{11.7} \mathrm{Si}_{1.3}$. Rare Met. 2006, 25, 556-561. [CrossRef]

293. Chau, N.; Thanh, P.Q.; Hoa, N.Q.; The, N.D. The existence of giant magnetocaloric effect and laminar structure in $\mathrm{Fe}_{73.5-\mathrm{x}} \mathrm{Cr}_{\mathrm{x}} \mathrm{Si}_{13.5} \mathrm{~B}_{9} \mathrm{Nb}_{3} \mathrm{Cu}_{1}$. J. Magn. Magn. Mater. 2006, 304, 36-40. [CrossRef]

294. Chau, N.; Hanh, D.T.; Tho, N.D.; Luong, N.H. Spin glass-like behavior, giant magnetocaloric and giant magnetoresistance effect in PrPb manganites. J. Magn. Magn. Mater. 2006, 303, E335-E338. [CrossRef]

295. Sun, L.; Yibole, H.; Tegus, O.; Guillou, F. Magnetocaloric Effect, Magnetoresistance of $\mathrm{Sc}_{0.28} \mathrm{Ti}_{0.72} \mathrm{Fe}_{2}$, and Phase Diagrams of $\mathrm{Sc}_{0.28} \mathrm{Ti}_{0.72} \mathrm{Fe}_{2-x} \mathrm{~T}_{\mathrm{x}}$ Alloys with $\mathrm{T}=\mathrm{Mn}$ or Co. Crystals 2020, 10, 410. [CrossRef]

296. Biswas, A.; Zarkevich, N.A.; Mudryk, Y.; Pathak, A.K.; Balema, V.; Johnson, D.D.; Pecharsky, V.K. Controlling magnetostructural transition and magnetocaloric effect in multi-component transition-metal-based materials. In preparation 2020.

297. Razaq, D.S.; Kurniawan, B.; Munazat, D.R.; Watanabe, K.; Tanaka, H. Role of Potassium Substitution in the Magnetic Properties and Magnetocaloric Effect in $\mathrm{La}_{0.8-\mathrm{x}} \mathrm{K}_{\mathrm{x}} \mathrm{Ba}_{0.05} \mathrm{Sr}_{0.15} \mathrm{MnO}_{3}(0 \leq \mathrm{x} \leq 0.20)$. Crystals 2020, 10, 407. [CrossRef]

298. Tegus, O.; Brück, E.; Buschow, K.H.J.; de Boer, F.R. Transition-metal-based magnetic refrigerants for room-temperature applications. Nature 2002, 415, 150-152. [CrossRef] [PubMed]

299. Gimaev, R.; Spichkin, Y.; Kovalev, B.; Kamilov, K.; Zverev, V.; Tishin, A. Review on magnetic refrigeration devices based on HTSC materials. Int. J. Refrig.-Rev. Int. Du Froid 2019, 100, 1-12. [CrossRef]

300. Tishin, A.M.; Spichkin, Y.I.; Zverev, V.I.; Egolf, P.W. A review and new perspectives for the magnetocaloric effect: New materials and local heating and cooling inside the human body. Int. J. Refrig.-Rev. Int. Du Froid 2016, 68, 177-186. [CrossRef]

301. Tishin, A.M.; Spichkin, Y.I. Recent progress in magnetocaloric effect: Mechanisms and potential applications. Int. J. Refrig.-Rev. Int. Du Froid 2014, 37, 223-229. [CrossRef]

302. Zarkevich, N.A. Structural database for reducing cost in materials design and complexity of multiscale computations. Complexity 2006, 11, 36-42. [CrossRef]

303. Wei, Z.-Y.; Liu, E.-K.; Li, Y.; Xu, G.-Z.; Zhang, X.-M.; Liu, G.-D.; Xi, X.-K.; Zhang, H.-W.; Wang, W.-H.; Wu, G.-H.; et al. Unprecedentedly Wide Curie-Temperature Windows as Phase-Transition Design Platform for Tunable Magneto-Multifunctional Materials. Adv. Electron. Mater. 2015, 1, 1500076. [CrossRef]

304. Maxwell, J.C.T. Theory of Heat; Longmans, Green, and Company: London, UK, 1872.

305. Kuz'min, M.D.; Tishin, A.M. Magnetocaloric effect. Part 1: An introduction to various aspects of theory and practice. Cryogenics 1992, 32, 545-558. [CrossRef]

306. Rosensweig, R.E. Heating magnetic fluid with alternating magnetic field. J. Magn. Magn. Mater. 2002, 252, 370-374. [CrossRef]

307. Kallumadil, M.; Tada, M.; Nakagawa, T.; Abe, M.; Southern, P.; Pankhurst, Q.A. Suitability of commercial colloids for magnetic hyperthermia. J. Magn. Magn. Mater. 2009, 321, 1509-1513. [CrossRef]

308. Landau, L.D.; Lifshitz, E.M. Statistical Physics, Part 1. In Course of Theoretical Physics; Butterworth-Heinemann: Oxford, UK, 1980; Volume 5.

309. Zverev, V.I.; Tishin, A.M.; Kuz'min, M.D. The maximum possible magnetocaloric $\Delta$ T effect. J. Appl. Phys. 2010, 107, 043907. [CrossRef]

310. Pecharsky, V.K.; Gschneidner, K.A.; Pecharsky, A.O.; Tishin, A.M. Thermodynamics of the magnetocaloric effect. Phys. Rev. B 2001, 64, 144406. [CrossRef]

311. Tishin, A.M. Magnetocaloric effect in the vicinity of magnetic phase transition. J. Magn. Magn. Mater. 1998, 184, 62-66. [CrossRef]

312. Kuz'min, M.D. Landau-type parametrization of the equation of state of a ferromagnet. Phys. Rev. B 2008, 77, 184431. [CrossRef]

313. Zverev, V.I.; Tishin, A.M.; Chernyshov, A.S.; Mudryk, Y.; Gschneidner, K.A., Jr.; Pecharsky, V.K. Magnetic and magnetothermal properties and the magnetic phase diagram of high purity single crystalline terbium along the easy magnetization direction. J. Phys. Condens. Matter 2014, 26, 066001. [CrossRef] [PubMed]

314. Zverev, V.I.; Tishin, A.M.; Min, Z.; Mudryk, Y.; Gschneidner, K.A., Jr.; Pecharsky, V.K. Magnetic and magnetothermal properties, and the magnetic phase diagram of single-crystal holmium along the easy magnetization direction. J. Phys. Condens. Matter 2015, 27, 146002. [CrossRef] 
315. Zarkevich, N.A.; Johnson, D.D. Shape-memory transformations of NiTi: Minimum-energy pathways between austenite, martensites, and kinetically limited intermediate states. Phys. Rev. Lett. 2014, 113, 265701. [CrossRef]

316. Zarkevich, N.A.; Johnson, D.D. Stable atomic structure of $\{$ NiTi $\}$ austenite. Phys. Rev. B 2014, 90, 060102. [CrossRef]

317. Ibarra, M.R.; Algarabel, P.A. Giant volume magnetostriction in the FeRh alloy. Phys. Rev. B 1994, 50, 4196-4199. [CrossRef]

318. Algarabel, P.A.; Ibarra, M.R.; Marquina, C.; del Moral, A.; Galibert, J.; Iqbal, M.; Askenazy, S. Giant room-temperature magnetoresistance in the FeRh alloy. Appl. Phys. Lett. 1995, 66, 3061-3063. [CrossRef]

319. Kouvel, J.S.; Hartelius, C.C. Anomalous Magnetic Moments and Transformations in the Ordered Alloy FeRh. J. Appl. Phys. 1962, 33, 1343-1344. [CrossRef]

320. Morellon, L.; Blasco, J.; Algarabel, P.A.; Ibarra, M.R. Nature of the first-order antiferromagnetic-ferromagnetic transition in the Ge-rich magnetocaloric compounds $\mathrm{Gd}_{5}\left(\mathrm{Si}_{\mathrm{x}} \mathrm{Ge}_{1-\mathrm{x}}\right)_{4}$. Phys. Rev. B 2000, 62, 1022-1026. [CrossRef]

321. du Tremolet de Lacheisserie, E. Magnetic properties and critical behaviour of $\mathrm{GdAl}_{2}$ : Thermal expansion, magnetization, magnetostriction and magnetocaloric effect. J. Magn. Magn. Mater. 1988, 73, 289-298. [CrossRef]

322. Zhang, J.; Zheng, Z.; Shan, G.; Bobev, S.; Shek, C.H. Abnormal thermal expansion, multiple transitions, magnetocaloric effect, and electronic structure of $\mathrm{Gd}_{6} \mathrm{Co}_{4.85}$. J. Appl. Phys. 2015, 118, 133903. [CrossRef]

323. Owens-Baird, B.; Sousa, J.P.S.; Ziouani, Y.; Petrovykh, D.Y.; Zarkevich, N.A.; Johnson, D.D.; Kolen'ko, Y.V.; Kovnir, K. Crystallographic facet selective HER catalysis: Exemplified in FeP and $\mathrm{NiP}_{2}$ single crystals. Chem. Sci. 2020, 11, 5007-5016. [CrossRef]

324. Qian, S.; Geng, Y.; Wang, Y.; Ling, J.; Hwang, Y.; Radermacher, R.; Takeuchi, I.; Cui, J. A review of elastocaloric cooling: Materials, cycles and system integrations. Int. J. Refrig. 2016, 64, 1-19. [CrossRef]

325. Tušek, J.; Engelbrecht, K.; Eriksen, D.; Dall'Olio, S.; Tušek, J.; Pryds, N. A regenerative elastocaloric heat pump. Nat. Energy 2016, 1, 16134. [CrossRef]

326. Mañosa, L.; Planes, A. Materials with Giant Mechanocaloric Effects: Cooling by Strength. Adv. Mater. 2017, 29, 1603607. [CrossRef] [PubMed]

327. Flerov, I.N.; Mikhaleva, E.A.; Gorev, M.V.; Kartashev, A.V. Caloric and multicaloric effects in oxygen ferroics and multiferroics. Phys. Solid State 2015, 57, 429-441. [CrossRef]

328. Binek, C.; Burobina, V. Near-room-temperature refrigeration through voltage-controlled entropy change in multiferroics. Appl. Phys. Lett. 2013, 102, 031915. [CrossRef]

329. Zarkevich, N.A.; Johnson, D.D. Magneto-structural transformations via a solid-state nudged elastic band method: Application to iron under pressure. J. Chem. Phys. 2015, 143, 064707. [CrossRef] [PubMed]

330. Czernuszewicz, A.; Kaleta, J.; Lewandowski, D. Multicaloric effect: Toward a breakthrough in cooling technology. Energy Convers. Manag. 2018, 178, 335-342. [CrossRef]

331. Liu, Y.; Phillips, L.C.; Mattana, R.; Bibes, M.; Barthélémy, A.; Dkhil, B. Large reversible caloric effect in FeRh thin films via a dual-stimulus multicaloric cycle. Nat. Commun. 2016, 7, 11614. [CrossRef] [PubMed]

332. Gottschall, T.; Gràcia-Condal, A.; Fries, M.; Taubel, A.; Pfeuffer, L.; Mañosa, L.; Planes, A.; Skokov, K.P.; Gutfleisch, O. A multicaloric cooling cycle that exploits thermal hysteresis. Nat. Mater. 2018, 17, 929-934. [CrossRef]

333. Cui, J.; Chu, Y.S.; Famodu, O.O.; Furuya, Y.; Hattrick-Simpers, J.; James, R.D.; Ludwig, A.; Thienhaus, S.; Wuttig, M.; Zhang, Z.; et al. Combinatorial search of thermoelastic shape-memory alloys with extremely small hysteresis width. Nat. Mater. 2006, 5, 286-290. [CrossRef] [PubMed]

334. Zhang, Z.; James, R.D.; Müller, S. Energy barriers and hysteresis in martensitic phase transformations. Acta Mater. 2009, 57, 4332-4352. [CrossRef]

335. Gutfleisch, O.; Gottschall, T.; Fries, M.; Benke, D.; Radulov, I.; Skokov, K.P.; Wende, H.; Gruner, M.; Acet, M.; Entel, P.; et al. Mastering hysteresis in magnetocaloric materials. Philos. Trans. R. Soc. A Math. Phys. Eng. Sci. 2016, 374, 20150308. [CrossRef]

336. Biswas, A.; Zarkevich, N.A.; Pathak, A.K.; Dolotko, O.; Hlova, I.Z.; Smirnov, A.V.; Mudryk, Y.; Johnson, D.D.; Pecharsky, V.K. First-order magnetic phase transition in $\operatorname{Pr}_{2} I n$ with negligible thermo-magnetic hysteresis. Phys. Rev. B 2020, 101, 224402. [CrossRef] 
337. Zverev, V.I.; Saletsky, A.M.; Gimaev, R.R.; Tishin, A.M.; Miyanaga, T.; Staunton, J.B. Influence of structural defects on the magnetocaloric effect in the vicinity of the first order magnetic transition in $\mathrm{Fe}_{50.4} \mathrm{Rh}_{49.6}$. Appl. Phys. Lett. 2016, 108, 192405. [CrossRef]

338. Zverev, V.I.; Pyatakov, A.P.; Shtil, A.A.; Tishin, A.M. Novel applications of magnetic materials and technologies for medicine. J. Magn. Magn. Mater. 2018, 459, 182-186. [CrossRef]

339. Yang, Y.; Walton, A.; Sheridan, R.; Güth, K.; Gauß, R.; Gutfleisch, O.; Buchert, M.; Steenari, B.-M.; Van Gerven, T.; Jones, P.T.; et al. REE Recovery from End-of-Life NdFeB Permanent Magnet Scrap: A Critical Review. J. Sustain. Metall. 2017, 3, 122-149. [CrossRef]

(C) 2020 by the authors. Licensee MDPI, Basel, Switzerland. This article is an open access article distributed under the terms and conditions of the Creative Commons Attribution (CC BY) license (http://creativecommons.org/licenses/by/4.0/). 